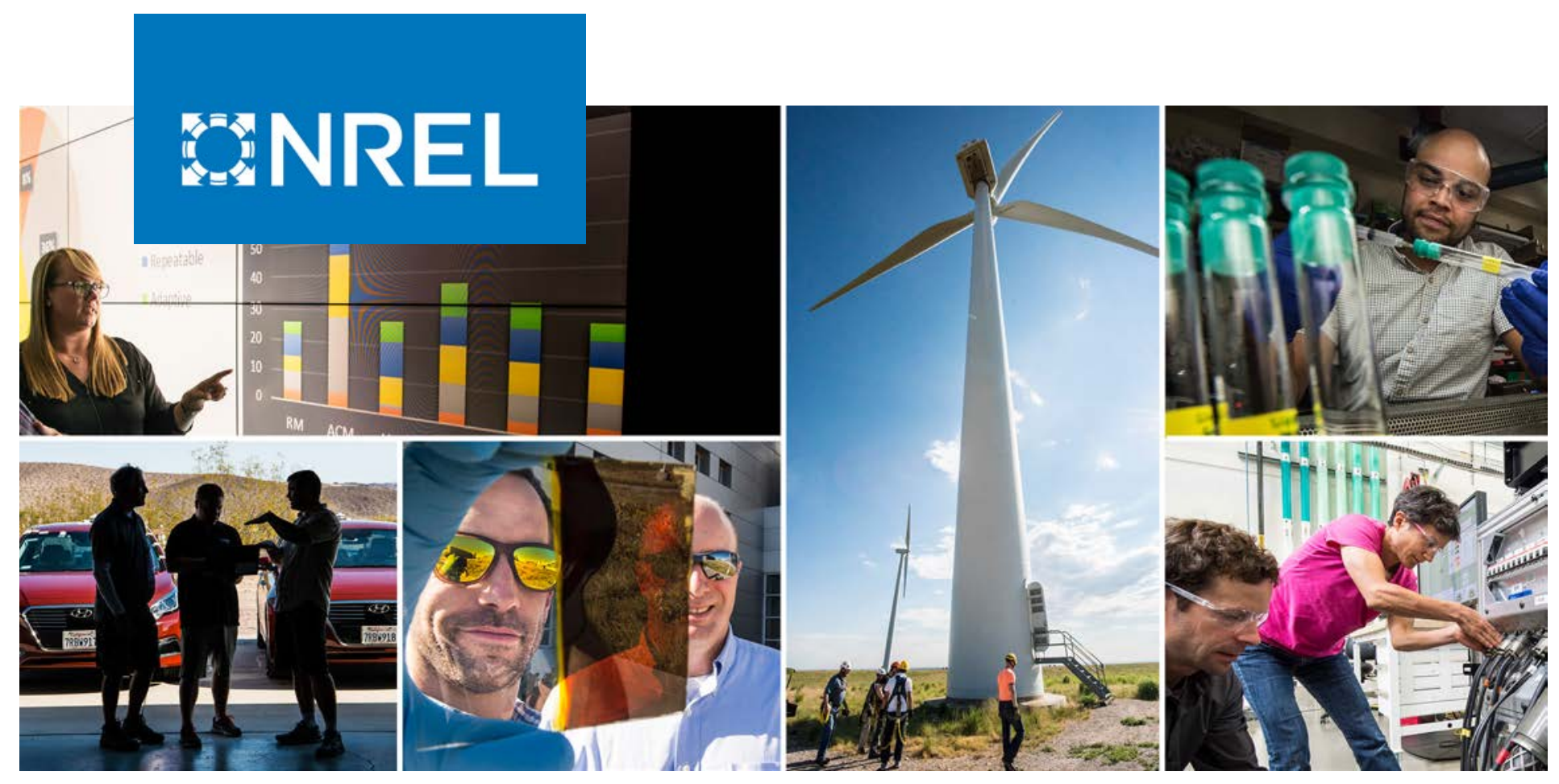

\title{
Scenario Evaluation and Regionalization Analysis (SERA) Model: Demand Side and Refueling Infrastructure Buildout
}

Brian Bush, Matteo Muratori, Chad Hunter, Jarett Zuboy, and Marc Melaina

National Renewable Energy Laboratory

NREL is a national laboratory of the U.S. Department of Energy Office of Energy Efficiency \& Renewable Energy

Operated by the Alliance for Sustainable Energy, LLC

This report is available at no cost from the National Renewable Energy Laboratory (NREL) at www.nrel.gov/publications.
Technical Report

NREL/TP-5400-70090 June 2019 


\section{GNREL}

Scenario Evaluation and

Regionalization Analysis

(SERA) Model: Demand Side and

Refueling Infrastructure Buildout

Brian Bush, Matteo Muratori, Chad Hunter, Jarett Zuboy, and Marc Melaina

National Renewable Energy Laboratory

\section{Suggested Citation}

Bush, Brian, Matteo Muratori, Chad Hunter, Jarett Zuboy, and Marc Melaina. 2019.

Scenario Evaluation and Regionalization Analysis (SERA) Model: Demand Side and

Refueling Infrastructure Buildout. Golden, CO: National Renewable Energy Laboratory.

NREL/TP-5400-70090. https://www.nrel.gov/docs/fy19osti/70090.pdf.

NREL is a national laboratory of the U.S. Department of Energy Office of Energy Efficiency \& Renewable Energy Operated by the Alliance for Sustainable Energy, LLC

This report is available at no cost from the National Renewable Energy Laboratory (NREL) at www.nrel.gov/publications.

Contract No. DE-AC36-08GO28308
Technical Report NREL/TP-5400-70090 June 2019

National Renewable Energy Laboratory 15013 Denver West Parkway Golden, CO 80401

303-275-3000 • www.nrel.gov 


\section{NOTICE}

This work was authored by the National Renewable Energy Laboratory, operated by Alliance for Sustainable Energy, LLC, for the U.S. Department of Energy (DOE) under Contract No. DE-AC36-08GO28308. Funding provided by the U.S. Department of Energy Office of Energy Efficiency and Renewable Energy Fuel Cell Technologies Office. The views expressed herein do not necessarily represent the views of the DOE or the U.S. Government.

This report is available at no cost from the National Renewable Energy Laboratory (NREL) at www.nrel.gov/publications.

U.S. Department of Energy (DOE) reports produced after 1991 and a growing number of pre-1991 documents are available free via www.OSTI.gov.

Cover Photos by Dennis Schroeder: (clockwise, left to right) NREL 51934, NREL 45897, NREL 42160, NREL 45891, NREL 48097, NREL 46526.

NREL prints on paper that contains recycled content. 


\section{Acknowledgments}

This work was supported by the U.S. Department of Energy (DOE) Office of Energy Efficiency and Renewable Energy Fuel Cell Technologies Office. The authors particularly appreciate the support and guidance provided by DOE program manager Fred Joseck for the development of the SERA model over multiple years. The authors wish to thank Kara Podkaminer (DOE), Miki Tomioka Crowell (California Air Resources Board), Andrew Martinez (California Air Resources Board), Elizabeth Connelly (National Renewable Energy Laboratory), and Jennifer Kurtz (National Renewable Energy Laboratory) who provided useful comments and reviews. 


\section{List of Acronyms}

DOE

EAM

U.S. Department of Energy

FCEV

Early Adopter Metric

HRS

Fuel cell electric vehicle

HSCC

LDV

Hydrogen refueling station

NREL

ROC

Hydrogen Station Capital Cost Calculator

Light-duty vehicle

National Renewable Energy Laboratory

Rest of the country

SERA

VMT

Scenario Evaluation and Regionalization Analysis model

ZEV

Vehicle miles traveled

Zero-emission vehicle 


\section{Executive Summary}

Hydrogen fuel cell electric vehicles (FCEVs) are a contender within a portfolio of options in the zero-emission vehicle market owing to their performance, range, and fast refueling time. However, market adoption of FCEVs is highly dependent on the convenient and cost-effective delivery of hydrogen to numerous demand centers, such as networks of urban retail hydrogen refueling stations.

The National Renewable Energy Laboratory's Scenario Evaluation and Regionalization Analysis (SERA) model estimates the number, size, and locations of hydrogen refueling stations that can satisfy the fuel demand from FCEVs and the hydrogen supply requirements to meet such a demand in terms of hydrogen production plants and delivery infrastructure. This report describes the demand-side capabilities of SERA for light-duty FCEVs. SERA simulates the systemwide cost-optimal evolution of hydrogen refueling infrastructure, providing insights that can reduce the informational and financial risks associated with infrastructure investment decisions and help accelerate the adoption of FCEVs. Various stakeholders have requested that the U.S. Department of Energy (DOE) support such analyses over the years, including the National Academies, DOE's federal advisory committee on hydrogen and fuel cells, and others. To address such recommendations, DOE's Fuel Cell Technologies Office has supported the development of various analysis tools and modeling efforts through its Systems Analysis subprogram over a decade. This work is part of a portfolio of strategic analysis activities to assess the needs, scenarios, and challenges associated with the rollout of FCEVs.

The SERA model's demand-side analysis includes three major phases:

1. Vehicle stock model-How large could hydrogen demand be?

Based on characteristics including annual vehicle sales, vehicle retirement rates, fuel economy, and vehicle miles driven, SERA determines the FCEV stock and the annual demand for hydrogen at an aggregate spatial resolution (e.g., at the state or national level).

2. Spatial disaggregation-Where will the hydrogen demand emerge over time? The hydrogen demand estimated in the previous step is spatially disaggregated into smaller regions, typically at the city level, based on likelihood of early FCEV adoption and strategic sequencing of hydrogen introduction into different regional markets.

3. Refueling network buildout - What are the characteristics of the refueling infrastructure network required to satisfy the evolving hydrogen demand? Given the hydrogen demand in each region (typically a city), SERA computes how many refueling stations are required to maximize coverage as well as the size of the stations deployed. It also computes the population that has access to a reliable hydrogen refueling network along with detailed financial performance on a station-by-station basis.

This report describes the SERA model's demand-side and refueling infrastructure buildout algorithms, and it also illustrates use of the model for simulating hydrogen refueling stations deployment scenarios using as an example the recent national hydrogen infrastructure report (Melaina, Bush et al. 2017) in support of H2USA. 


\section{Table of Contents}

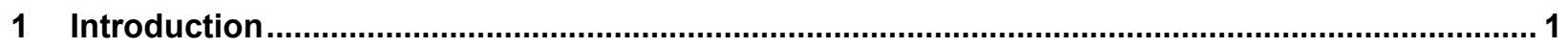

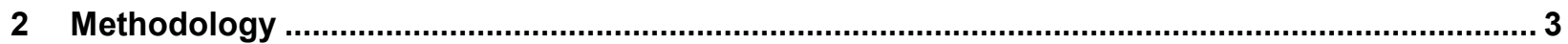

2.1 Vehicle Stock Model: Translating Vehicle Sales into Aggregate Hydrogen Demand................. 3

2.2 Spatial Disaggregation: Projecting Where Hydrogen Demand Emerges over Time .................... 6

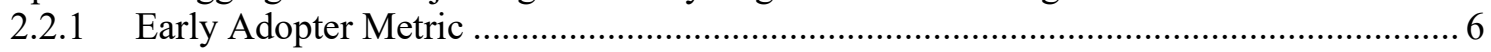

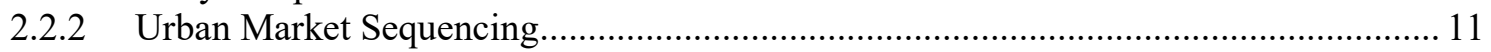

2.3 Refueling Network Buildout: Characterizing the Hydrogen Infrastructure Network ............... 13

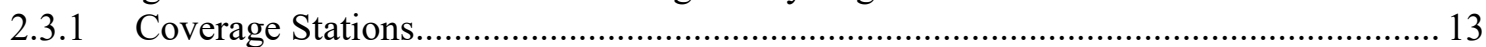

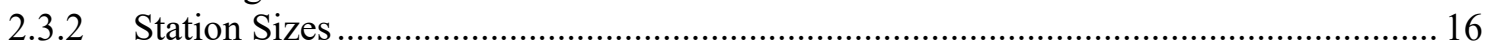

2.3.3 Population Enabled ......................................................................... 18

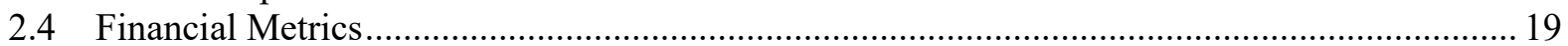

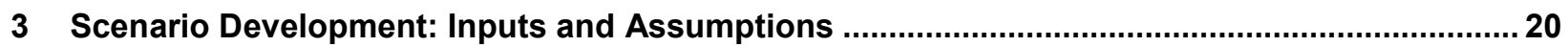

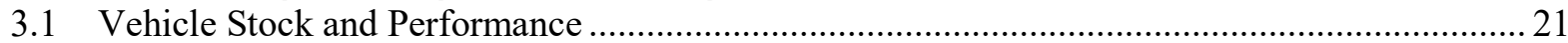

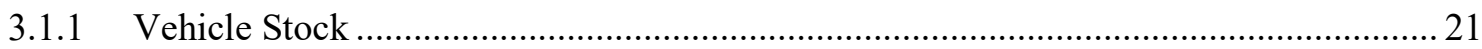

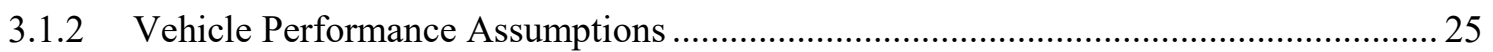

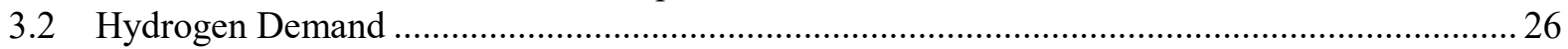

3.2.1 Urban Market Sequencing..................................................................... 27

3.2.2 Expanding Local Networks: Clustered vs. Dispersed Local Demand .......................... 28

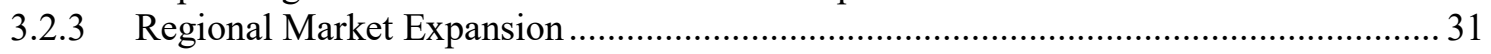

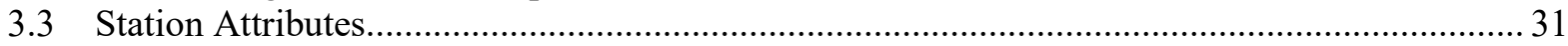

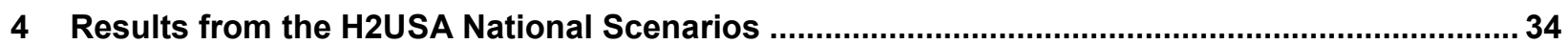

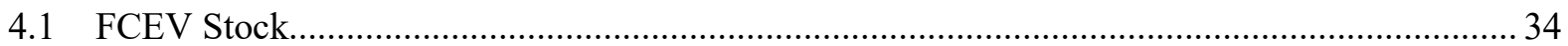

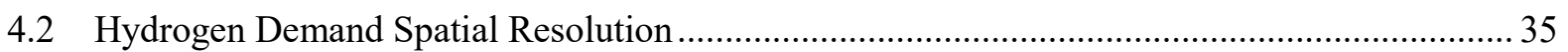

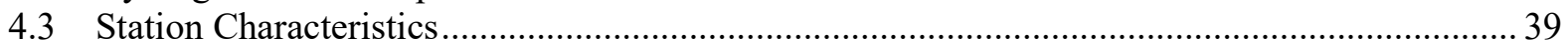

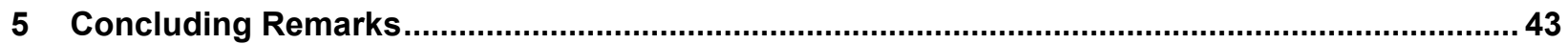

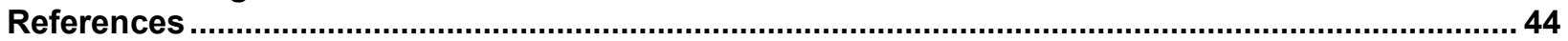




\section{List of Figures}

Figure 1. Overall SERA demand-side and refueling infrastructure buildout modeling scheme.................. 3

Figure 2. Inputs (red arrows) and outputs (green arrows) in the SERA vehicle stock model...................... 5

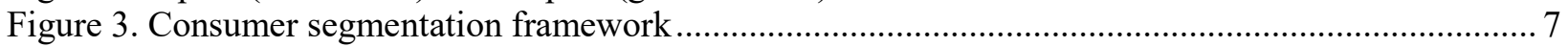

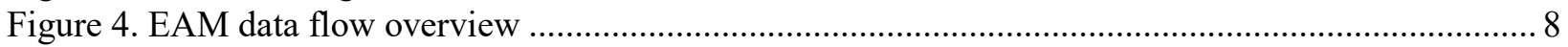

Figure 5. Prioritization of urban markets by EAM density and EAM per coverage station ...................... 12

Figure 6. Economies of scale for hydrogen station dispensing cost, not including hydrogen production and delivery costs, based on the Hydrogen Delivery Scenario Analysis Model (ANL 2018) for gaseous (GH2) and liquid (LH2) hydrogen delivery to the station by trucks ....................... 14

Figure 7. Urban boundaries and EAM density with coverage stations in Seattle..................................... 15

Figure 8. Example of coverage stations required (circle size and labels) for pairs of urban areas with similar populations but distinct population densities ........................................................ 16

Figure 9. Generic station capacity distribution: the chart is interpreted, for example, as saying that $20 \%$ of the stations (reading on the horizontal axis) are at least $150 \%$ of the average station capacity

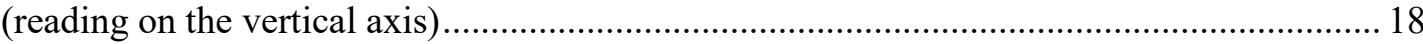

Figure 10. FCEV sales by scenario compared with total U.S. LDV sales .............................................2 22

Figure 11. Early California FCEV stock by scenario compared with Assembly Bill 8 survey values (blue

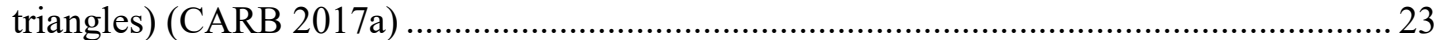

Figure 12. Breakdown of FCEV sales by period and region for the Urban Markets, State Success, and

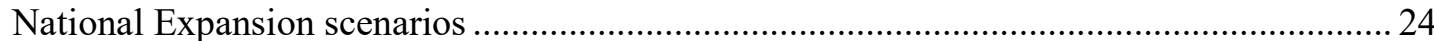

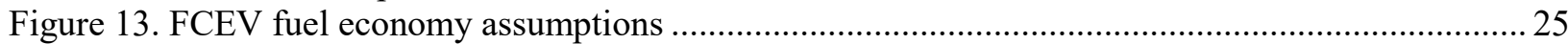

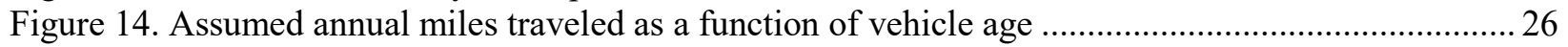

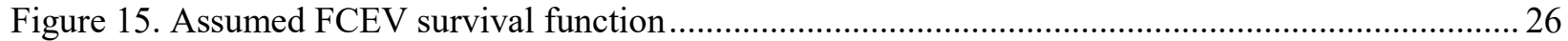

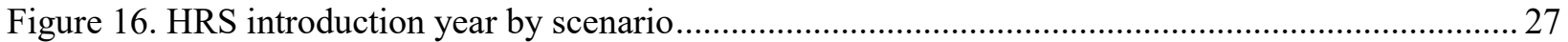

Figure 17. Examples of highly clustered and highly dispersed local networks and resulting HRS

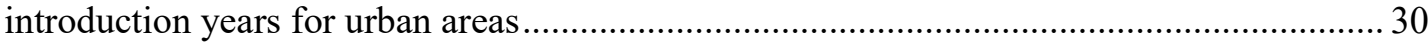

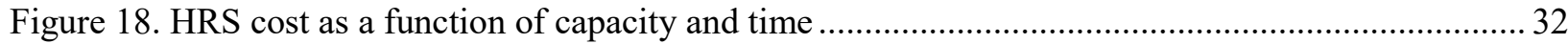

Figure 19. Average new station capacity versus normalized demand density based on EAM................. 33

Figure 20. Number of FCEVs on the road and total HRSs by scenario and region................................. 34

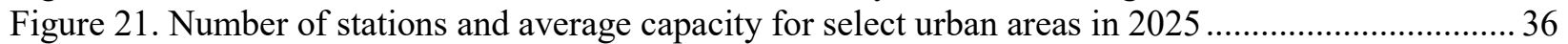

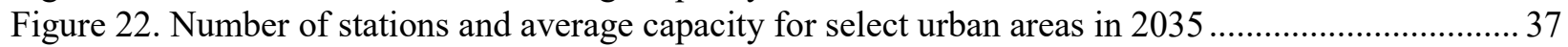

Figure 23. Number of stations and average capacity for select urban areas in 2050 .............................. 38

Figure 24. Total and new hydrogen refueling capacity and average station utilization by scenario and over

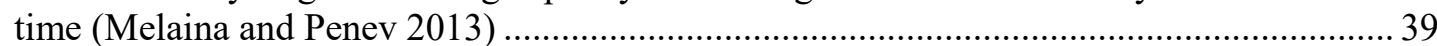

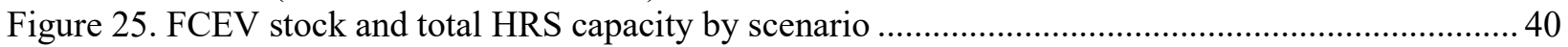

Figure 26. Average capacity of new HRSs deployed over time by region and scenario .......................... 40

Figure 27. Number and average size of HRSs in 2050 for each scenario........................................... 41

Figure 28. Population with access to hydrogen refueling by scenario................................................... 42

\section{List of Tables}

Table 1. Urban Area EAM Rankings (Based on Share of Total Nationwide EAM) and Characteristics for the 100 Urban Areas with the Highest EAM Shares.............................................................. 9

Table 2. Market Trends by Scenario (from Melaina, Bush et al. 2017) ................................................. 20 


\section{Introduction}

In the United States, the transportation sector accounts for more petroleum consumption than any other sector and is responsible for a large share of total energy use and emissions (EIA 2017; IPCC 2014). Zero-emission vehicles (ZEVs) could reduce transportation-related petroleum use and carbon dioxide emissions while also reducing pollution in urban areas. Hydrogen fuel cell electric vehicles (FCEVs) are a contender in the ZEV market owing to their performance, range, and fast refueling time. FCEVs are attracting increased attention from global business leaders as a key trend in the automotive marketplace (KPMG 2017). In addition, FCEVs could become more highly integrated with the electricity grid, providing synergistic opportunities for grid modernization (BNEF 2017; Melaina and Eichman 2015). However, market adoption of FCEVs is highly dependent on the convenient and cost-effective delivery of hydrogen to numerous demand centers, such as networks of urban retail hydrogen refueling stations (HRS) (Ogden 1999; Melaina, Muratori et al. 2017). Once an effective hydrogen refueling infrastructure is in place, FCEV adoption would be based primarily on vehicle attributes rather than availability of refueling infrastructure (Melaina, Bremson, and Solo 2012; CaFCP 2012; CARB 2017a; Baronas et al. 2017).

The National Renewable Energy Laboratory's (NREL's) Scenario Evaluation and Regionalization Analysis (SERA) model estimates the number, size, and locations of HRSs that could satisfy the fuel demand from FCEVs and the hydrogen supply requirements to meet such a demand in terms of hydrogen production plants and delivery infrastructure. The demand-side capabilities of SERA, described in this report, simulate the systemwide cost-optimal evolution of hydrogen refueling infrastructure, providing insights that can reduce the informational and financial risks associated with infrastructure investment decisions and help accelerate the adoption of FCEVs. The SERA model's demand-side analysis includes three major phases (Muratori et al. 2018):

1. Vehicle stock model-How large could hydrogen demand be? Based on characteristics including annual vehicle sales, vehicle retirement rates, fuel economy, and vehicle miles driven, SERA determines the FCEV stock and the annual demand for hydrogen at an aggregate spatial resolution (e.g., at the state or national level).

2. Spatial disaggregation-Where will the hydrogen demand emerge over time? The hydrogen demand estimated in the previous step is spatially disaggregated into smaller regions, typically at the city level, based on likelihood of early FCEV adoption and strategic sequencing of hydrogen introduction into different regional markets.

3. Refueling network buildout - What are the characteristics of the refueling infrastructure network required to satisfy the evolving hydrogen demand? Given the hydrogen demand in each region (typically a city), SERA computes how many refueling stations are required to maximize coverage as well as the size of the stations deployed. It also computes the population that has access to a reliable hydrogen refueling network along with detailed financial performance on a station-by-station basis.

This report describes the SERA model's demand-side and refueling infrastructure buildout algorithms, and it also illustrates use of the model for simulating HRS deployment scenarios using as an example the recent H2USA national hydrogen infrastructure report (Melaina, Bush et 
al. 2017) in support of H2USA. Section 2 describes the methodology, input-output relationships, and flow of equations for the three SERA demand-side modeling steps. Section 3 details development of the national H2USA scenarios, and Section 4 reviews scenario results, including additional detailed results supporting the H2USA national scenarios report. The SERA model is regularly improved and enhanced; this report describes the SERA capability at the end of 2017. 


\section{Methodology}

This section describes the modeling methodology used to project spatially and temporally resolved dynamics of HRS rollout in the SERA model, as summarized in Figure 1 (Muratori et al. 2018). First, based on vehicle characteristics and exogenous FCEV adoption rates, a vehicle stock model computes aggregate hydrogen demand. Second, the vehicle adoption and associated hydrogen demand are spatially disaggregated to capture differences between the different geographic areas considered. Finally, the expansion of the hydrogen refueling network over time is modeled to mimic strategic station deployment aimed at maximizing the network coverage, effectiveness, and profitability.

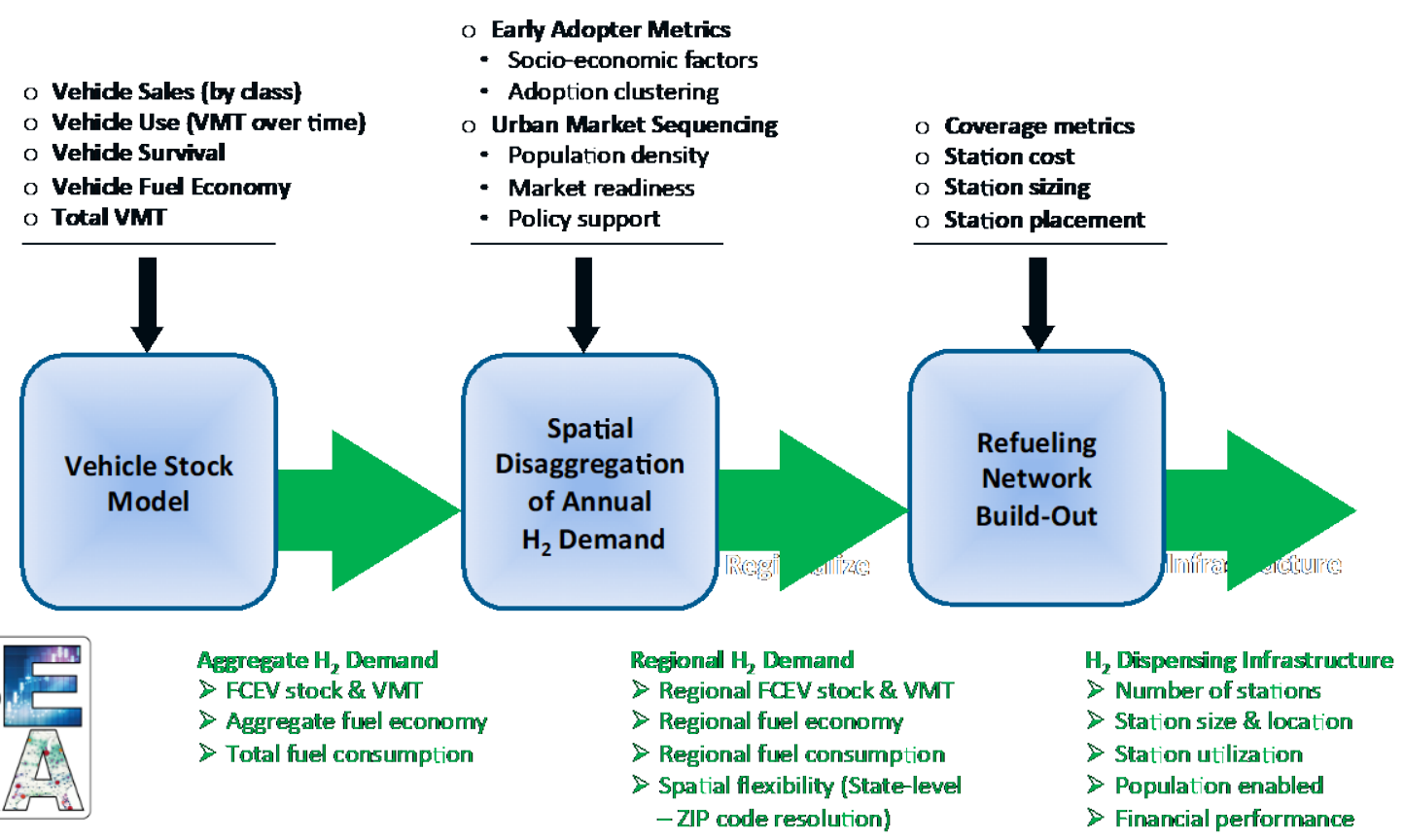

Figure 1. Overall SERA demand-side and refueling infrastructure buildout modeling scheme

\subsection{Vehicle Stock Model: Translating Vehicle Sales into Aggregate Hydrogen Demand}

The SERA vehicle stock model accounts for alternative fuel vehicle introductions and corresponding fuel demand by tracking vehicle population over time at a regional level. The basic vehicle stock accounting framework is consistent with other vehicle stock models, such as Argonne National Laboratory's VISION model (ANL 2017) and variations of the VISION model used for recent National Research Council reports (Leiby and Rubin 2003; NRC 2008; NRC 2013). These functions include equations for tracking vehicle miles traveled, vehicle survival rates, net fuel economy, and net fuel consumption over the decades of analysis. The vehicle stock module's specific capabilities include the following:

- Incorporate user-defined set of vehicle types (internal combustion engine vehicles, FCEVs, electric vehicles, etc.) and classes (light-duty vehicle [LDV], medium-duty vehicle, heavy-duty vehicle) 
- Apply fuel economy trends for different vehicle types and fuel choices as they evolve over time

- Analyze any user-defined set of geographic regions (ZIP codes, counties, states, census regions, national level, etc.)

- Allow customized vehicle miles traveled (VMT) and survival/scrappage rates for particular vehicle types and ages

- Support the use of different algorithms and customized inputs for vehicle choice outcomes and market shares

- Estimate annual fleet VMT based upon vehicle age

- Generate fuel consumption results based upon annual vehicle stock, fuel economy trends, and total miles driven by different vehicle types

- Provide fuel demand outputs suitable for use as inputs into the SERA supply-side infrastructure optimization model.

Figure 2 illustrates inputs and outputs of the SERA vehicle stock model. Input sources could include market share results from prescriptive studies or detailed vehicle choice models (e.g., the Automotive Deployment Options Projection Tool, ADOPT [Brooker et al. 2015]) and attributes of exogenous scenarios used to explore alternative transportation futures (e.g., total vehicles sold per year). Specific inputs include the following (for more details please refer to http://nrel.github.io/sera/sera-manual.html):

1. Total vehicle sales: This is a table of new vehicles sold (whose type is not distinguished) by region and year. Each row corresponds to a geographic region, each column corresponds to the year, and the entries in the table specify the count of new vehicles sold in a given region in a given year.

2. Market share: This is a table of fractions of vehicles sold by type per year. Each region has a row in the table for each vehicle type, each column corresponds to the year, and the entries in the table specify the fraction (value between zero and one) of new vehicles of a given type introduced in a given region and year.

3. Vehicle use: This is a table of how many miles each vehicle drives by each vehicle type (e.g., light-duty FCEVs) as a function of the vehicle's age, region, and model year. Each row corresponds to a specific vehicle, vocation, region, age, and model year (columns).

4. Vehicle survival: This is a table of what fraction of vehicles in a given region and of a given age and type survive to the subsequent year. It represents vehicle retirements, sometimes called "scrappage."

5. Fuel split: This is a table of fractions of the fuel used in each vehicle type (for vehicles that can use more than one fuel) in each year. Each row corresponds to the fuel type a particular vehicle type is using in that year. Because each vehicle type may be able to use multiple types of fuel (e.g., a plug-in hybrid electric vehicle might use gasoline, E85, and electricity), the entries in the table (i.e., the last columns) specify the fractions of the miles that the given vehicle type drives using the given type of fuel. 
6. Fuel economy: This is a table of fuel efficiency (miles per gasoline gallon equivalent) by fuel type, vehicle type, and model year. Each row corresponds to the fuel type a particular vehicle type is using, each column corresponds to the model year of the vehicle, and the entries in the table specify the fuel economy (in miles per gasoline gallon equivalent) for the vehicle using a given fuel in a given year.

7. Total VMT: This is a table of VMT by region and year. Each row corresponds to a geographic region, each column corresponds to the year, and the entries in the table specify the aggregate VMT for all vehicles from a given region in a given year.

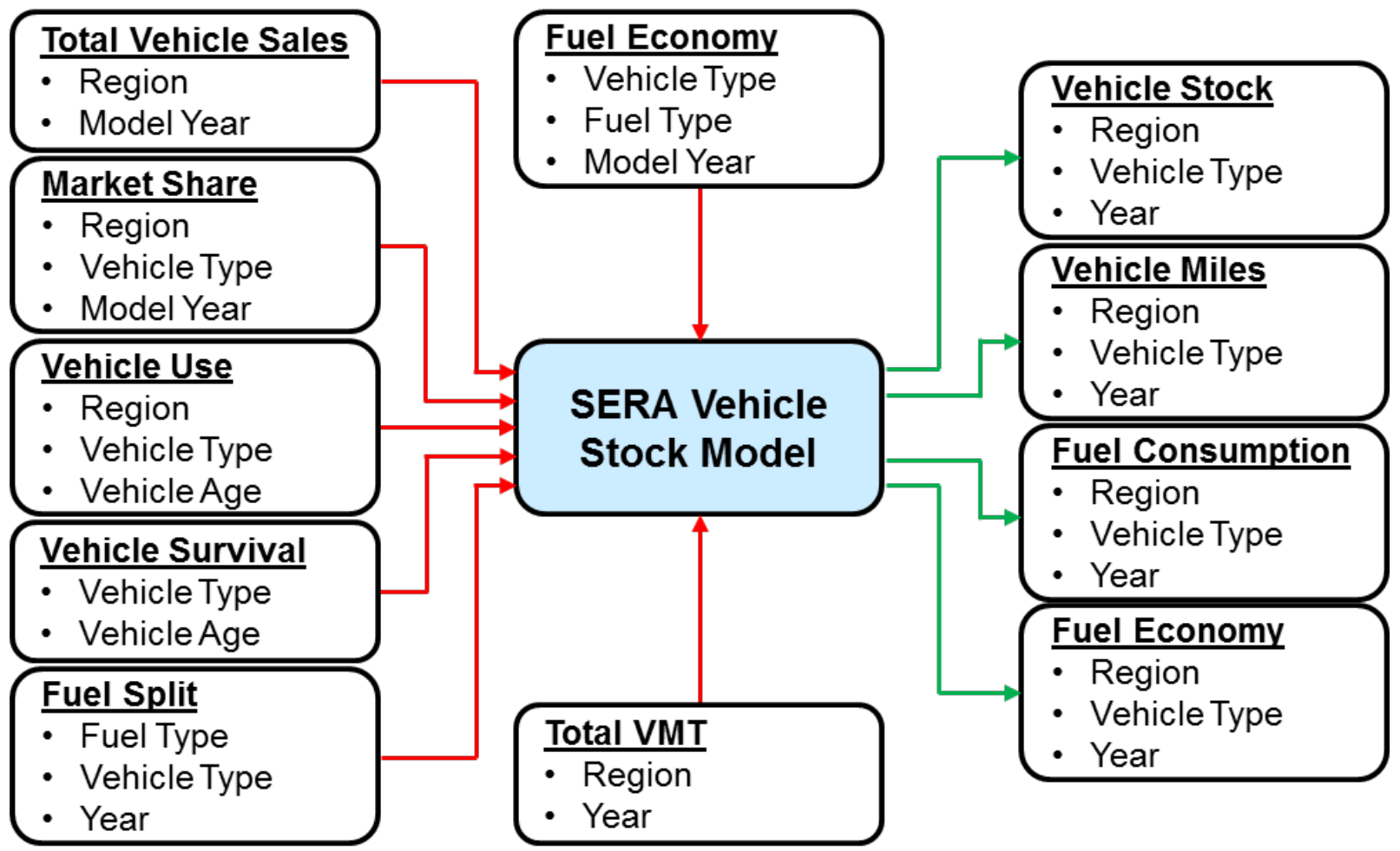

Figure 2. Inputs (red arrows) and outputs (green arrows) in the SERA vehicle stock model

Based on all the inputs, the stock model calculates the vehicle population in each region and year being analyzed. The output tables from the model include the following:

1. Vehicle stock: Total vehicles on the road by region, vehicle type, and year.

2. Vehicle miles: Annual miles traveled by region, vehicle type, and year.

3. Fuel consumption: Total fuel used by region, vehicle type, and year.

4. Fuel economy: Travel-weighted-average fuel economy by region, vehicle type, and year.

These outputs then become inputs to the next step, in which the SERA model disaggregates fuel demand into smaller regions, as described in the following section. 


\subsection{Spatial Disaggregation: Projecting Where Hydrogen Demand Emerges over Time}

In this step, the regional hydrogen demand calculated using SERA's vehicle stock model is spatially disaggregated into smaller regions, typically the urban area level as in the H2USA report (Melaina, Bush et al. 2017). Projecting detailed hydrogen demand locations provides the geographical framework to deploy the refueling infrastructure for supporting FCEV adoption. Because hydrogen infrastructure design and cost are highly dependent on spatial characteristics (e.g., demand density, value of land, cost of energy commodities), this disaggregation of demand is very important to the overall optimization of the hydrogen infrastructure network (Yang and Ogden 2013). In addition, increasing the spatial resolution of hydrogen demand can be useful for determining the synergies between hydrogen production, storage, and transmission options, and the local electricity grid (Turton and Moura 2008). The SERA model's demand disaggregation algorithm is based on the likelihood of early FCEV adoption based on early adopter metrics and the strategic sequencing of hydrogen introduction into different urban markets, as described below.

\subsubsection{Early Adopter Metric}

As FCEV markets grow, different segments of consumers will begin to purchase vehicles. This evolution can be envisioned in terms of five consumer categories: innovators, early adopters, early majority, late majority, and laggards (Figure 3) (Rogers 2003). Many new technologies depend on segments of consumers who are willing to pay a premium for the product. In cases with strong network externalities, these consumers may also have a high tolerance for limited service or utility during the early phases of product rollout. For example, a sparse HRS network may be tolerated to some degree by innovators and early adopters, but early majority consumers are more likely to expect refueling availability equivalent or similar to that currently offered by gasoline stations. Widely available HRSs may contribute to what has been referred to as the "chasm" between early adopters and the mainstream market for FCEVs (Egbue and Long 2012; Heffner, Kurani, and Turrentine 2007). Similarly, for FCEV adoption to expand into the early and late majority market segments, it is likely that FCEV performance, price, and make and model diversity must be at least comparable to, if not superior to, the characteristics of conventional gasoline vehicles offered today. This consumer segmentation framework is useful in describing FCEV market depth within any particular urban area or region over time.

While many new advanced electric-drive vehicles have been introduced into the LDV market in recent years (IEA 2017), knowledge about consumer responsiveness to FCEVs and the depth of the various consumer segments is very limited owing to a lack of empirical data. While three FCEV models are commercially available in California, only a few thousand vehicles are on the road, and sale trends over time are limited (Baronas et al. 2017; CARB 2017a). For this reason, SERA uses a proxy metric to predict the differential adoption of FCEVs over time. 


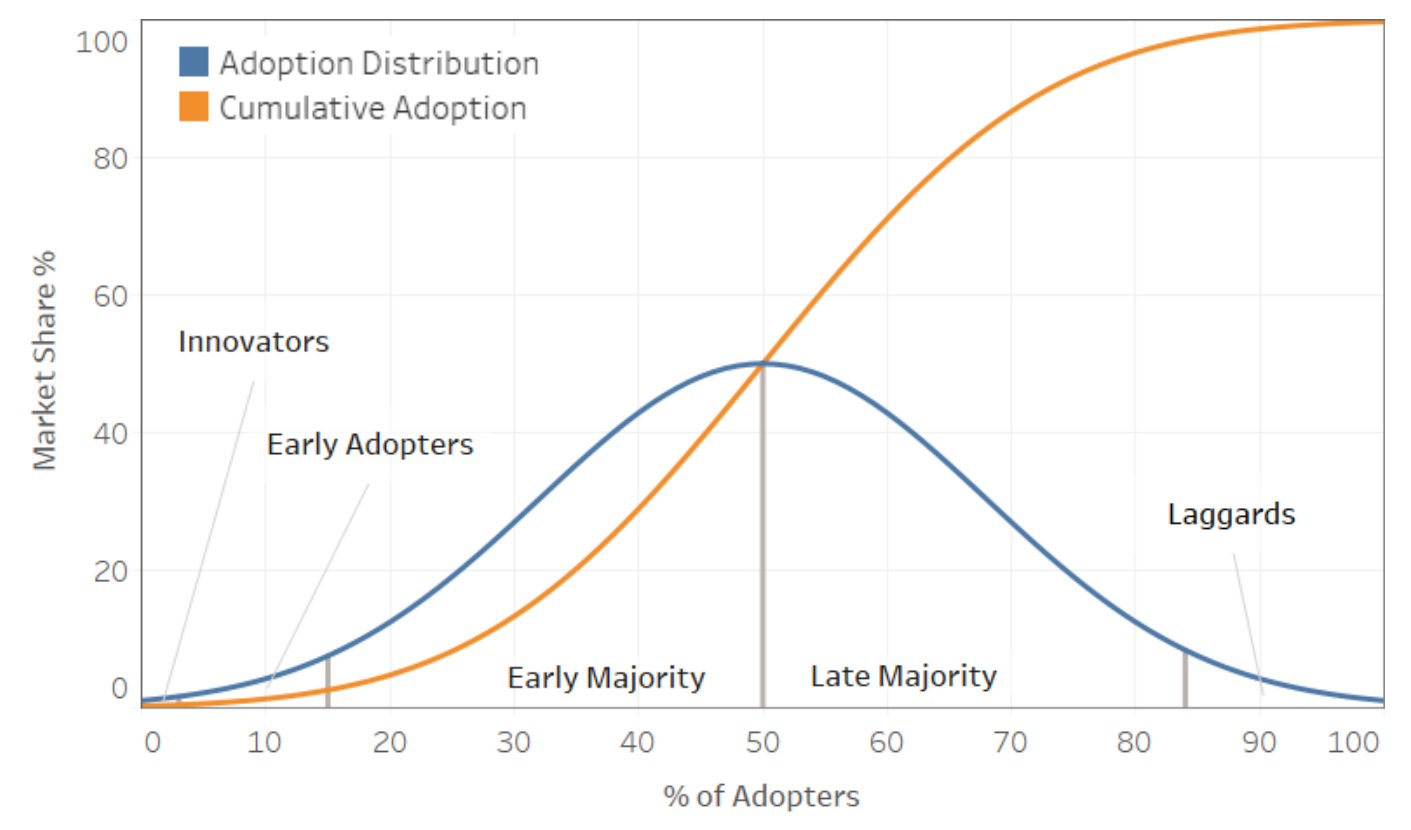

Figure 3. Consumer segmentation framework

The Early Adopter Metric (EAM) is the proxy metric used in the SERA analysis to predict the differential adoption of FCEVs over time. Many studies have assessed empirical data or projected theoretical models of future consumer responses to advanced electric-drive vehicle attributes (e.g., Melaina and Bremson 2008; Hidrue et al. 2011). The EAM relies on actual advanced and luxury vehicle sales (revealed preferences) as well as household income data (Melaina, Bremson, and Solo 2012). The EAM is determined for a given area (EAM doesn't change in time within one specific SERA run) as follows:

$$
E A M=0.5 A V+0.25 L V+0.25 H I
$$

where $A V$ is the area's number of sales of advanced vehicles (hybrid electric vehicles, plug-in hybrid electric vehicles, and battery electric vehicles), $L V$ is the area's number of sales of luxury vehicles, ${ }^{1}$ and $H I$ is the number of households with annual income greater than $\$ 100,000\left(70^{\text {th }}\right.$ percentile of households) (U.S. Census 2017). The selection and weighting of these three factors is based on NREL's experience with vehicle-choice data and modeling (Brooker et al. 2015; Melaina, Bremson, and Solo 2012; Melaina 2009) and consultation with industry experts.

The EAM captures a broad range of existing factors contributing to the adoption of advanced electric-drive vehicles. Some advanced vehicle markets may have matured more quickly owing to incentives, and others may have progressed because of consumer preferences for vehicle attributes (e.g., acceleration, driving experience). The EAM captures the outcome of both influences. Including household income accounts for the correlation between advanced and luxury vehicle sales and expendable income without relying on more theoretical assumptions about market segmentation or matching vehicle attributes to consumer preferences. Although ongoing research into consumer preferences will provide more comprehensive metrics as new

\footnotetext{
${ }^{1}$ As defined in the IHS Markit automotive vehicle registration data (IHS Markit 2017).
} 
market data are assessed over time, the EAM is a useful proxy for current analyses because of its transparency, simplicity, and grounding in readily available national data.

The EAM is used in the SERA analysis in various ways. Each urban area is characterized by dividing its EAM by the total EAM across all urban areas nationwide. The resulting rankings of urban areas by share of total EAM are used to represent the relative latent early adopter demand for FCEVs. For example, the Los Angeles area has about 11\% of the total nationwide EAM, the New York City area has about 9\%, and the Chicago area has about $4 \%$. All else being equal, a hypothetical early introduction of FCEVs ${ }^{2}$ would result in about $11 \%$ of the FCEVs being deployed in the Los Angeles area, about 9\% in the New York City area, and about 4\% in the Chicago area. It is important to note that each urban area has early adopters and that the EAM ranks geographic areas according to the propensity for early adoption: as discussed below, EAM rankings are used to algorithmically model the sequence in which FCEVs will be introduced into urban areas. Table 1 ranks the 100 urban areas with the highest EAM shares. ${ }^{3}$

However, the EAM share in each urban area does not alone characterize the geographic hydrogen demand that would drive refueling station buildout over time. Rather, two additional metrics define which urban areas have early adopter demand and are also likely to be effective markets for refueling infrastructure investments: EAM density $\left(\mathrm{EAM} / \mathrm{mi}^{2}\right)$ and EAM per coverage station, which is a small HRS network built early during FCEV introduction so that fueling opportunities, and thus vehicle adoption, are initially available in the area (see Section 2.3.1 for further information about coverage stations). Table 1 provides these values for the top 100 urban areas. Numerical values for EAM density and EAM per coverage station are computed assuming a total EAM of approximately 65 million across the entire country, for illustrative purposes.

Figure 4 illustrates how the various early adopter metrics are computed, highlighting how the number of coverage stations does not depend on EAM, but their location and timing does. Section 2.2.2 describes how SERA uses both values to prioritize urban areas for FCEV and refueling station deployment over time.

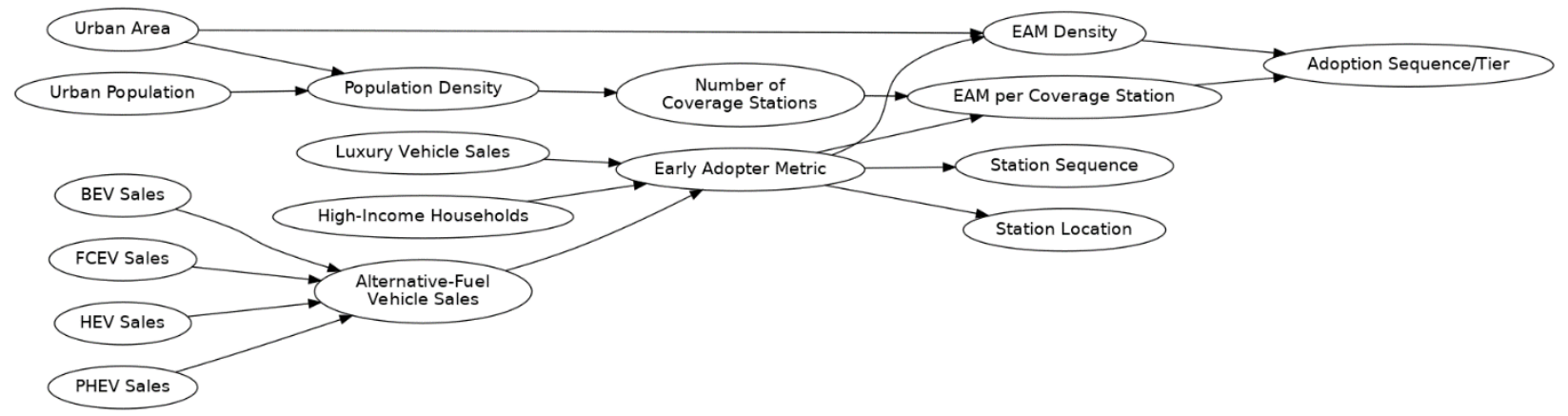

Figure 4. EAM data flow overview

\footnotetext{
${ }^{2}$ The overall size of the U.S. early adopter market will depend on various factors and industry choices.

${ }^{3}$ These 100 urban areas contain 166 million residents, or $76 \%$ of all 219 million residents within a total of 482 urban areas (2010 census values).
} 
Table 1. Urban Area EAM Rankings (Based on Share of Total Nationwide EAM) and Characteristics for the 100 Urban Areas with the Highest EAM Shares

\begin{tabular}{|c|c|c|c|c|c|c|}
\hline Urban Area Name & $\%$ EAM & $\begin{array}{c}\text { Population } \\
\text { Density } \\
\text { [ppl/mi²] }\end{array}$ & Population & Area $\left[\mathrm{mi}^{2}\right]$ & $\mathrm{EAM} / \mathrm{mi}^{2}$ & $\begin{array}{c}\text { EAM/Coverage } \\
\text { Station }\end{array}$ \\
\hline Los Angeles—Long Beach-Anaheim, CA & 10.6185 & 6,910 & $12,150,996$ & 1,759 & 3,816 & 394,751 \\
\hline New York-Newark, NY-NJ-CT & 8.6315 & 5,061 & $18,351,295$ & 3,626 & 1,505 & 92,458 \\
\hline Chicago, IL-IN & 4.4022 & 3,465 & $8,608,208$ & 2,485 & 1,120 & 41,524 \\
\hline San Francisco-Oakland, CA & 3.805 & 6,217 & $3,281,212$ & 528 & 4,556 & 343,529 \\
\hline Washington, DC-VA-MD & 3.7007 & 3,397 & $4,586,770$ & 1,350 & 1,732 & 61,547 \\
\hline Atlanta, GA & 2.9195 & 1,685 & $4,515,419$ & 2,680 & 688 & 14,415 \\
\hline Seattle, WA & 2.7809 & 2,870 & $3,059,393$ & 1,066 & 1,648 & 48,819 \\
\hline Boston, $\mathrm{MA}-\mathrm{NH}-\mathrm{RI}$ & 2.6929 & 2,144 & $4,181,019$ & 1,950 & 873 & 21,011 \\
\hline Miami, FL & 2.6186 & 4,193 & $5,502,379$ & 1,312 & 1,261 & 57,066 \\
\hline Philadelphia, PA—NJ-DE-MD & 2.6131 & 2,685 & $5,441,567$ & 2,026 & 815 & 23,260 \\
\hline San Diego, CA & 2.3665 & 3,879 & $2,956,746$ & 762 & 1,962 & 78,715 \\
\hline Dallas_Fort Worth—Arlington, TX & 2.3663 & 2,817 & $5,121,892$ & 1,818 & 823 & 24,516 \\
\hline San Jose, CA & 2.177 & 5,834 & $1,664,496$ & 285 & 4,822 & 275,172 \\
\hline Houston, TX & 2.0332 & 2,914 & $4,944,332$ & 1,697 & 757 & 23,362 \\
\hline Phoenix-Mesa, AZ & 1.6425 & 3,155 & $3,629,114$ & 1,150 & 902 & 29,658 \\
\hline Minneapolis—St. Paul, MN—WI & 1.3886 & 2,390 & $2,650,890$ & 1,109 & 791 & 20,408 \\
\hline Detroit, Ml & 1.3696 & 2,724 & $3,734,090$ & 1,371 & 632 & 18,033 \\
\hline Portland, OR-WA & 1.2813 & 3,428 & $1,849,898$ & 540 & 1,501 & 50,610 \\
\hline Denver-Aurora, CO & 1.2474 & 3,483 & $2,374,203$ & 682 & 1,157 & 41,490 \\
\hline Sacramento, CA & 1.1611 & 3,625 & $1,723,634$ & 475 & 1,543 & 56,448 \\
\hline Baltimore, MD & 1.1165 & 2,963 & $2,203,663$ & 744 & 949 & 28,224 \\
\hline Tampa-St. Petersburg, FL & 1.0259 & 2,370 & $2,441,770$ & 1,030 & 629 & 16,209 \\
\hline St. Louis, MO—IL & 0.8354 & 2,301 & $2,150,706$ & 935 & 565 & 13,894 \\
\hline Austin, TX & 0.768 & 2,589 & $1,362,416$ & 526 & 922 & 24,268 \\
\hline Mission Viejo_-Lake Forest-San Clemente, CA & 0.7643 & 3,864 & 583,681 & 151 & 3,197 & 96,603 \\
\hline Concord, CA & 0.7432 & 3,009 & 615,968 & 205 & 2,294 & 58,709 \\
\hline Cincinnati, $\mathrm{OH}-\mathrm{KY}-\mathrm{IN}$ & 0.6773 & 2,043 & $1,624,827$ & 795 & 538 & 12,229 \\
\hline Bridgeport-Stamford, CT-NY & 0.6635 & 1,949 & 923,311 & 474 & 885 & 19,061 \\
\hline Orlando, FL & 0.6586 & 2,316 & $1,510,516$ & 652 & 638 & 15,416 \\
\hline Las Vegas-Henderson, NV & 0.6564 & 4,525 & $1,886,011$ & 417 & 995 & 46,096 \\
\hline Riverside-San Bernardino, CA & 0.6464 & 3,529 & $1,932,666$ & 548 & 746 & 25,532 \\
\hline Cleveland, $\mathrm{OH}$ & 0.6453 & 2,289 & $1,780,673$ & 778 & 524 & 12,745 \\
\hline Charlotte, $\mathrm{NC}-\mathrm{SC}$ & 0.617 & 1,610 & $1,249,442$ & 776 & 502 & 9,998 \\
\hline Pittsburgh, PA & 0.6103 & 1,880 & $1,733,853$ & 922 & 418 & 9,184 \\
\hline Columbus, $\mathrm{OH}$ & 0.6072 & 2,632 & $1,368,035$ & 520 & 738 & 19,188 \\
\hline Kansas City, MO-KS & 0.6023 & 2,222 & $1,519,417$ & 684 & 557 & 13,125 \\
\hline Indianapolis, IN & 0.5663 & 2,071 & $1,487,483$ & 718 & 498 & 11,545 \\
\hline San Antonio, TX & 0.5496 & 2,922 & $1,758,210$ & 602 & 577 & 16,540 \\
\hline Virginia Beach, VA & 0.5111 & 2,585 & $1,439,666$ & 557 & 580 & 15,381 \\
\hline Raleigh, NC & 0.5108 & 1,695 & 884,891 & 522 & 618 & 12,417 \\
\hline Milwaukee, WI & 0.5084 & 2,454 & $1,376,476$ & 561 & 573 & 14,605 \\
\hline Providence, $\mathrm{RI}-\mathrm{MA}$ & 0.466 & 2,066 & $1,190,956$ & 576 & 511 & 11,326 \\
\hline Hartford, CT & 0.4274 & 1,761 & 924,859 & 525 & 514 & 10,389 \\
\hline Jacksonville, FL & 0.3967 & 1,752 & $1,065,219$ & 608 & 412 & 8,357 \\
\hline Nashville-Davidson, TN & 0.3878 & 1,674 & 969,587 & 579 & 423 & 8,452 \\
\hline Richmond, VA & 0.3598 & 1,896 & 953,556 & 503 & 452 & 9,474 \\
\hline Salt Lake City—West Valley City, UT & 0.3387 & 3,692 & $1,021,243$ & 277 & 774 & 26,753 \\
\hline Louisville/Jefferson County, KY-IN & 0.3193 & 2,040 & 972,546 & 477 & 412 & 9,172 \\
\hline Sarasota-Bradenton, FL & 0.3169 & 1,748 & 643,260 & 368 & 544 & 10,540 \\
\hline Memphis, TN-MS—AR & 0.2836 & 2,112 & $1,060,061$ & 502 & 357 & 8,148 \\
\hline
\end{tabular}




\begin{tabular}{|c|c|c|c|c|c|c|}
\hline Urban Area Name & $\%$ EAM & $\begin{array}{c}\text { Population } \\
\text { Density } \\
{\left[p p l / \mathrm{mi}^{2}\right]}\end{array}$ & Population & Area $\left[\mathrm{mi}^{2}\right]$ & $\mathrm{EAM} / \mathrm{mi}^{2}$ & EAM/Cov. Stn. \\
\hline Oklahoma City, OK & 0.2732 & 2,053 & 861,505 & 420 & 411 & 9,087 \\
\hline Buffalo, NY & 0.2672 & 2,434 & 935,906 & 384 & 439 & 10,555 \\
\hline Rochester, NY & 0.2659 & 2,192 & 720,572 & 329 & 511 & 11,205 \\
\hline Fresno, CA & 0.2642 & 3,819 & 654,628 & 171 & 974 & 27,829 \\
\hline New Haven, CT & 0.2574 & 1,809 & 562,839 & 311 & 523 & 10,169 \\
\hline Birmingham, AL & 0.2571 & 1,406 & 749,495 & 533 & 305 & 5,602 \\
\hline Albany-Schenectady, NY & 0.2542 & 2,012 & 594,962 & 296 & 533 & 11,474 \\
\hline New Orleans, LA & 0.2521 & 3,365 & 899,703 & 267 & 596 & 17,706 \\
\hline Omaha, NE-IA & 0.2515 & 2,628 & 725,008 & 276 & 576 & 14,450 \\
\hline Tucson, AZ & 0.2454 & 2,376 & 843,168 & 355 & 437 & 10,339 \\
\hline Tulsa, OK & 0.2326 & 1,948 & 655,479 & 336 & 437 & 9,188 \\
\hline Albuquerque, NM & 0.2255 & 2,925 & 741,318 & 253 & 562 & 14,250 \\
\hline Bonita Springs, FL & 0.2189 & 1,553 & 310,298 & 200 & 692 & 12,578 \\
\hline Thousand Oaks, CA & 0.2147 & 2,484 & 214,811 & 86 & 1,569 & 27,139 \\
\hline Allentown, $\mathrm{PA}-\mathrm{NJ}$ & 0.2137 & 1,905 & 664,651 & 349 & 387 & 7,946 \\
\hline Dayton, $\mathrm{OH}$ & 0.2131 & 2,046 & 724,091 & 354 & 381 & 8,416 \\
\hline Cape Coral, FL & 0.2015 & 1,442 & 530,290 & 368 & 346 & 6,368 \\
\hline Worcester, MA-CT & 0.1915 & 1,537 & 486,514 & 317 & 382 & 7,121 \\
\hline Denton-Lewisville, TX & 0.1896 & 2,489 & 366,174 & 147 & 815 & 17,117 \\
\hline Springfield, MA-CT & 0.1866 & 1,736 & 621,300 & 358 & 329 & 6,551 \\
\hline Charleston-North Charleston, SC & 0.1852 & 1,805 & 548,404 & 304 & 385 & 7,802 \\
\hline Madison, WI & 0.1839 & 2,531 & 401,661 & 159 & 732 & 16,602 \\
\hline Knoxville, TN & 0.1821 & 1,265 & 558,696 & 442 & 261 & 4,604 \\
\hline Santa Clarita, CA & 0.1779 & 3,414 & 258,653 & 76 & 1,484 & 28,110 \\
\hline Des Moines, IA & 0.1748 & 2,219 & 450,070 & 203 & 545 & 11,049 \\
\hline Colorado Springs, CO & 0.174 & 2,974 & 559,409 & 188 & 585 & 15,710 \\
\hline Columbia, SC & 0.1617 & 1,429 & 549,777 & 385 & 266 & 4,867 \\
\hline Murrieta-Temecula-Menifee, CA & 0.1604 & 2,730 & 441,546 & 162 & 623 & 14,482 \\
\hline Grand Rapids, MI & 0.1604 & 1,989 & 569,935 & 286 & 354 & 7,239 \\
\hline Harrisburg, PA & 0.1598 & 1,654 & 444,474 & 269 & 376 & 7,216 \\
\hline Santa Rosa, CA & 0.1559 & 3,131 & 308,231 & 98 & 1,001 & 24,638 \\
\hline Durham, NC & 0.1522 & 1,894 & 347,602 & 183 & 524 & 9,617 \\
\hline Akron, $\mathrm{OH}$ & 0.1486 & 1,714 & 569,499 & 332 & 283 & 5,525 \\
\hline Poughkeepsie-Newburgh, NY-NJ & 0.1445 & 1,216 & 423,566 & 348 & 262 & 4,347 \\
\hline Baton Rouge, LA & 0.1435 & 1,601 & 594,309 & 371 & 244 & 4,534 \\
\hline Palm Bay_Melbourne, FL & 0.1348 & 1,619 & 452,791 & 280 & 305 & 5,681 \\
\hline Winston-Salem, NC & 0.1344 & 1,201 & 391,024 & 326 & 261 & 4,471 \\
\hline Toledo, $\mathrm{OH}-\mathrm{MI}$ & 0.1303 & 2,061 & 507,643 & 246 & 334 & 6,862 \\
\hline Vallejo, CA & 0.1295 & 3,809 & 165,074 & 43 & 1,888 & 27,278 \\
\hline Barnstable Town, MA & 0.1294 & 824 & 246,695 & 300 & 273 & 4,090 \\
\hline Wichita, KS & 0.1281 & 2,167 & 472,870 & 218 & 371 & 8,094 \\
\hline Oxnard, CA & 0.128 & 4,270 & 367,260 & 86 & 941 & 26,966 \\
\hline Greenville, SC & 0.1276 & 1,246 & 400,492 & 321 & 251 & 4,246 \\
\hline Greensboro, NC & 0.1246 & 1,649 & 311,810 & 189 & 416 & 7,157 \\
\hline Port St. Lucie, FL & 0.1235 & 1,652 & 376,047 & 228 & 343 & 6,506 \\
\hline Trenton, NJ & 0.1221 & 2,789 & 296,668 & 106 & 725 & 15,428 \\
\hline Nashua, $\mathrm{NH}-\mathrm{MA}$ & 0.1188 & 1,212 & 226,400 & 187 & 402 & 6,259 \\
\hline Lancaster, PA & 0.1174 & 1,610 & 402,004 & 250 & 297 & 5,302 \\
\hline Conroe-The Woodlands, TX & 0.1146 & 1,800 & 239,938 & 133 & 545 & 9,052 \\
\hline Ann Arbor, MI & 0.1128 & 1,859 & 306,022 & 165 & 433 & 7,918 \\
\hline
\end{tabular}




\subsubsection{Urban Market Sequencing}

SERA's urban market sequencing algorithm estimates how FCEVs and hydrogen stations could be introduced into various urban markets over time to reach the greatest number of early adopters with a limited number of HRS. Figure 5 plots EAM density (horizontal axis) and EAM per coverage station (vertical axis) for the top 100 urban areas. Assuming a limited number of coverage stations deployed nationally, the urban areas toward the top right corner of Figure 5 would receive coverage stations first, followed by other urban areas below and to the left of the high-priority areas, with areas near the bottom left corner having the lowest priority. For example, the Tier 1 California cities of Los Angeles, San Francisco-Oakland, and San Jose have an EAM per coverage station of more than 250,000. California's Mission Viejo and San Diego are also included in Tier 1 because of a combination of relatively high EAM density and EAM per coverage station. Tier 2 areas such as New York-Newark and Seattle sit lower along one or both axes. The EAM per coverage station ratio drops by half moving downward into Tier 3 and by a factor of five moving from Tier 2 to Tier 4 . Many urban areas have a relatively high EAM, owing to a large proportion of hybrid electric vehicle and plug-in hybrid electric vehicle sales, but fall into Tier 3 or Tier 4 because of low population density and the large number of coverage stations required. Tier cutoffs are selected to prioritize station deployment based on EAM per coverage station and EAM density as well as regional proximity between cities in the same tier.

The SERA algorithm starts with a base introduction year, which prioritizes the introduction year for an urban area $c$ in proportion to the urban area's percentile of EAM relative to other urban areas:

$$
\text { Base year } r_{c}=(\text { First year })+\left(\text { EAM percentile } e_{c} / 100\right) *(\text { Last year }- \text { First year }),
$$

where First year is the first year when FCEVs become commercially available for sale and Last year is the last year when FCEVs are introduced anywhere; the EAM percentiles are sorted from highest to lowest value of EAM.

The SERA algorithm then adjusts these base years using three additional parameters to project HRS deployment over time in different geographic regions: specific introduction year, delay parameter, and clustering effect. The specific introduction year is a user-defined parameter that can force FCEV adoption and HRS deployment in a specific region to simulate the temporal status of existing or planned infrastructure and future trends or commitments, such as awards made through the California Assembly Bill 8 program (Baronas et al. 2017). The delay parameter postpones FCEV and HRS introduction in regions where the demand is less than a predetermined threshold to avoid deploying FCEVs too early in markets that are not mature enough for hydrogen: algorithmically, the base year for introduction is delayed by a constant (the delay parameters) times the EAM percentile in the urban area. The clustering parameter captures niches and synergies related to refueling station placement in clusters of regions and early adoption areas. In particular, small regions that are close to larger regions experiencing rapid FCEV adoption will experience spillover effects and increased FCEV adoption and HRS deployment. The clustering effect is computed by averaging each urban area's introduction year with those of nearby urban areas, with the numerical value of the weighting factor being the clustering parameter itself. This parameter captures market effects for vehicle adoption; studies show that alternative fuel vehicle adoption is characterized by significant clustering effects driven by socioeconomic and behavioral factors influencing the decision of individual customers 
to buy different vehicles that correlate with household location (Mohseni and Stevie 2010; Kahn and Vaughn 2009). The parameter also captures convenience effects related to more convenient FCEV refueling in a regional cluster.
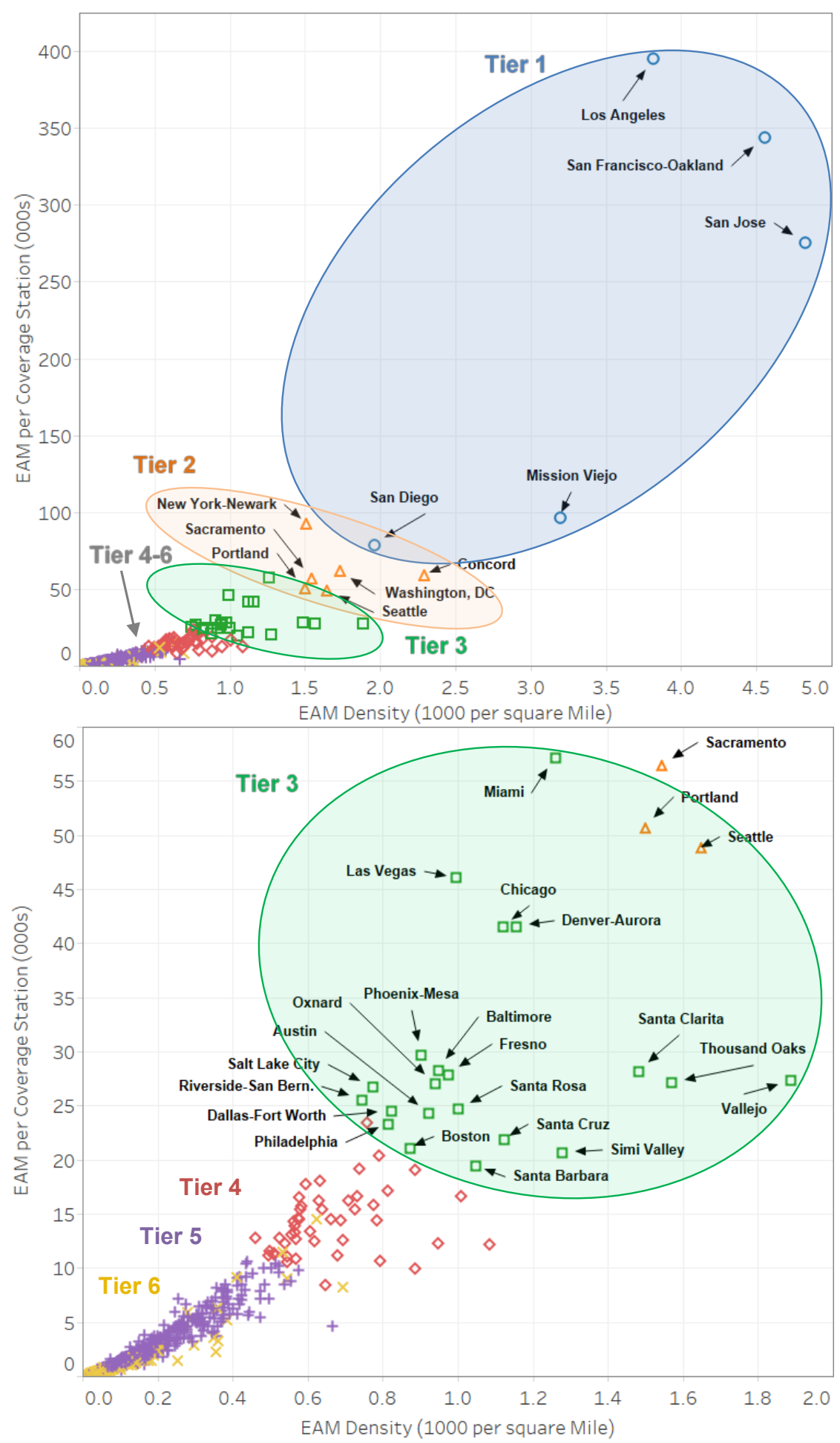

Figure 5. Prioritization of urban markets by EAM density and EAM per coverage station 


\subsection{Refueling Network Buildout: Characterizing the Hydrogen Infrastructure Network}

In this final step, the SERA model uses the geospatially resolved hydrogen demand to determine the optimal locations and deployment schedule for HRSs. Its approach reduces investment risks by targeting more mature markets first and thus maximizing station utilization. The model also calculates the financial performance of each station over time and provides valuable information to potential stakeholders about the optimal network buildout.

\subsubsection{Coverage Stations}

Hydrogen station economics depend strongly on station utilization. The faster a new station attracts FCEV drivers and achieves high utilization rates, the more quickly investors can receive an adequate return on investment.

Station size is also an important economic factor. Larger stations - benefiting from strong economies of scale - will have lower costs per kilogram of hydrogen dispensed and will typically be able to offer lower retail hydrogen prices and higher investor returns. Figure 6 illustrates hydrogen station economies of scale, with declining levelized hydrogen dispensing costs for stations supplied by gaseous and liquid truck delivery (the costs reported include dispensing costs only and do not include the cost of hydrogen delivered to the station, including production and delivery costs) (ANL 2018). ${ }^{4}$ Based on industry-vetted cost estimates, station economics appear favorable for relatively large hydrogen stations. For example, assuming high economies of scale, stations sized in the range of 500-1,000 kg/day (which corresponds to 100200 refueling events per day for an average car) of installed capacity are expected to lead to a dispensing cost - which is the cost to build and operate refueling stations, not the total retail hydrogen cost — of \$2-\$3/kg (based on the U.S. Department of Energy's Hydrogen Delivery Scenario Analysis Model [ANL 2018]). It is important to note that current markets are at considerably lower economies of scale, and the retail price of hydrogen also includes the cost of hydrogen production and distribution infrastructure. The cost of hydrogen delivery and dispensing in early markets has been estimated at $\sim \$ 12-\$ 13 / \mathrm{kg}$ (DOE 2018).

\footnotetext{
${ }^{4}$ The costs of hydrogen production and potential liquefaction are not considered in Figure 6 because they would occur upstream rather than at the refueling station itself. Figure 6 also does not consider the logistical challenges of gaseous hydrogen truck delivery, which increase as station size and number of required deliveries increase. Large stations with gaseous hydrogen delivered by trucks might become logistically impractical and cost prohibitive.
} 


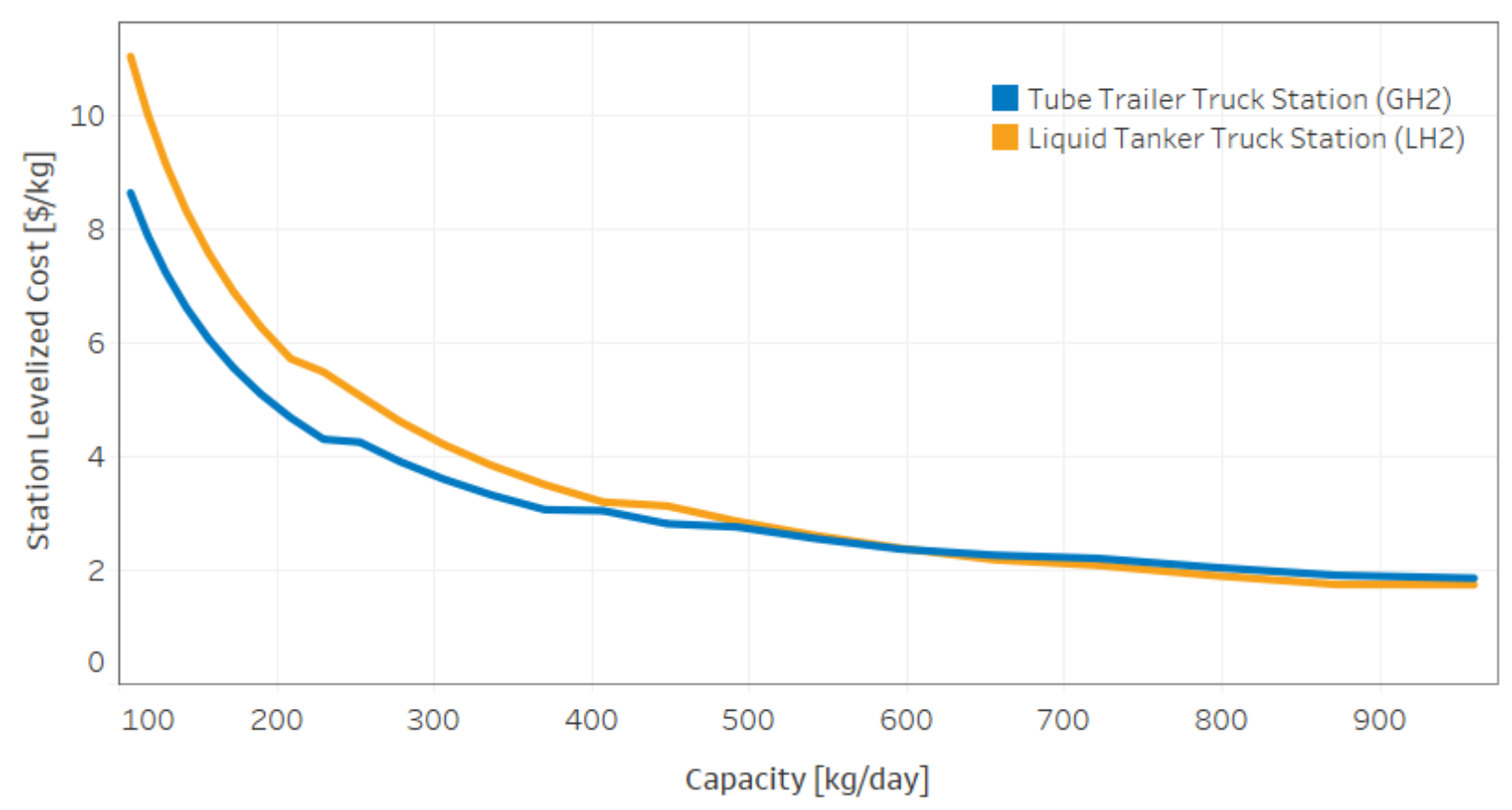

Figure 6. Economies of scale for hydrogen station dispensing cost, not including hydrogen production and delivery costs, based on the Hydrogen Delivery Scenario Analysis Model (ANL 2018) for gaseous (GH2) and liquid (LH2) hydrogen delivery to the station by trucks

The economic benefits of high station utilization and large station sizes, however, are difficult to realize in early markets because of two fundamental and countervailing trends. First, a basic level of convenient refueling coverage must be in place before most consumers will be comfortable purchasing an FCEV - typically requiring station access near their homes and along major roads in their areas (Melaina, Bremson, and Solo 2012). Many consumers will also place significant value on stations located along interstates connecting their urban area to other destinations. As the benefits of expanded HRS networks increase, station availability will become an increasingly small factor in consumer purchase decisions, allowing markets to grow in response to relative vehicle attributes such as cost and performance. Second, the relatively large number of stations needed to provide this base coverage level in early markets delays the introduction of large stations with strong economies of scale. The result is a market-development challenge, with the rate of FCEV adoption and resulting HRS network utilization being key indicators of investment success.

Multiple studies have estimated the number of stations required to provide an acceptable level of coverage to a large number of early adopters (Baronas et al. 2017; CARB 2017a; Nicholas, Handy, and Sperling 2004; Melaina 2003; Stephens-Romero et al. 2010; Kuby et al. 2009). The SERA model follows guidance used to develop the California Fuel Cell Partnership Roadmap report (CaFCP 2012), which assumes that residents in a given area must be able to access an HRS within some average travel time ( $\sim 6$ minutes) before widespread FCEV adoption can proceed (Melaina, Bremson, and Solo 2012). The "coverage stations" are the bare minimum

\footnotetext{
${ }^{5}$ Analytically, the calculation correlates average travel time with urban area population density based on an assessment of travel patterns and optimal station locations in Los Angeles, San Francisco, San Diego, and Sacramento. For details, see Nicholas, Handy, and Sperling (2004).
} 
number of stations that are needed for all parts of an urban area to be within 6 minutes' travel of an HRS.

For example, Figure 7 shows the location of 28 coverage stations estimated for the Seattle urban area, which give access to residents within 6 minutes of average travel time. The buffers around each station indicate 6-minute drive times, although precision at the street-corner level is not the focus of the coverage algorithm. Instead, the first coverage stations provide service to the areas of highest EAM, and subsequent stations expand outward to other high-EAM areas. Color coding shows the first set of seven stations as red, second set as yellow, third set as green, and fourth set as blue. Coverage stations for nearby urban areas would be installed as those cities are added to the local station network.

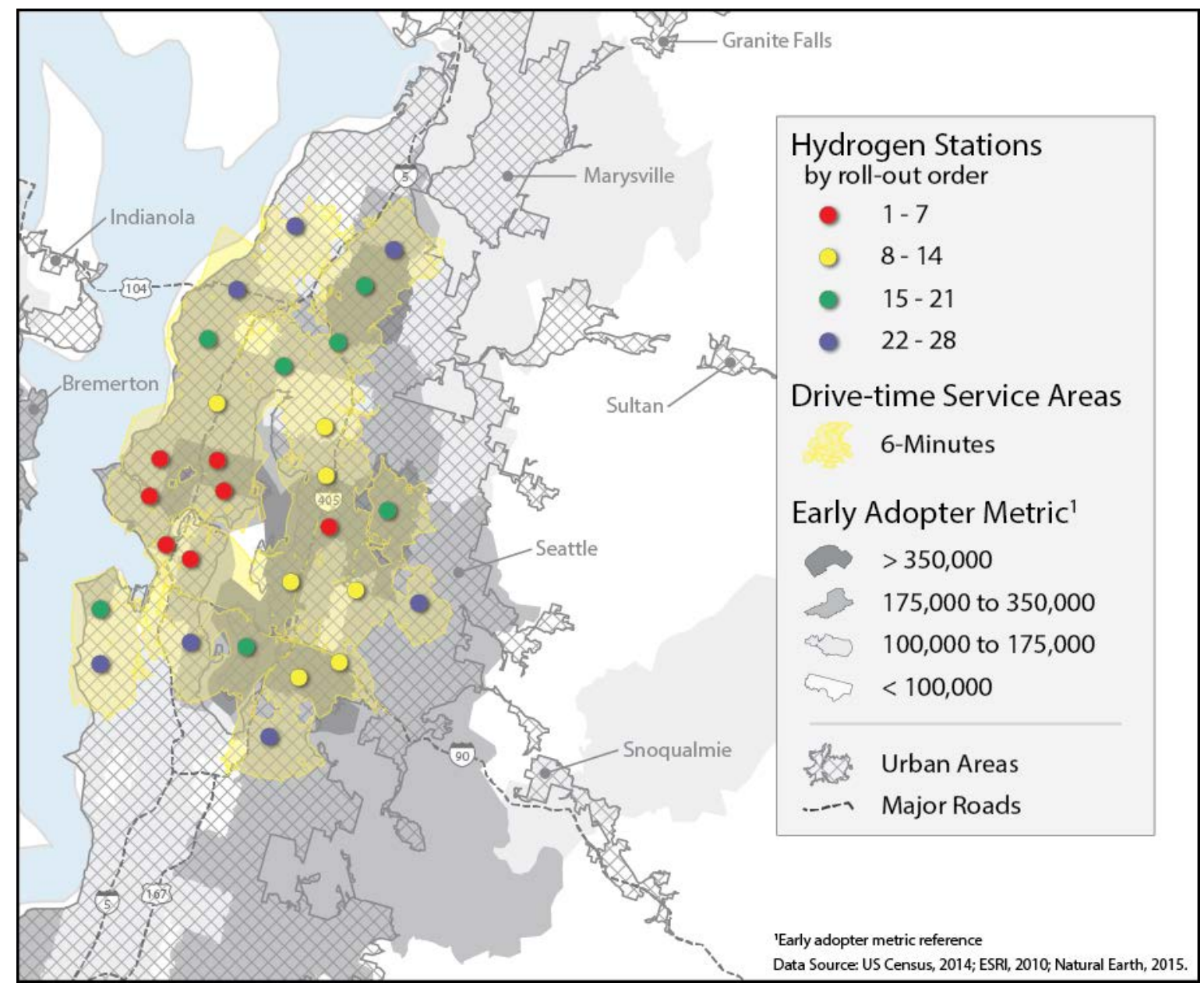

Figure 7. Urban boundaries and EAM density with coverage stations in Seattle

Figure 8 shows the number of coverage stations required for three pairs of urban areas-each pair consisting of two cities with a similar population but different population density-to illustrate the impact of population density on the number of required coverage stations (based on NREL analysis inspired by the approach in Nicholas, Handy, and Sperling [2004], assuming that the number of coverage stations $=1+8.1503640 * \exp (-0.0003241 *$ Population / Area $) *$ (Area/ 100), which is a function posited by expert judgment and with parameters chosen to yield 
6-minute-travel-time geographic coverage for most cities, despite their varied population and area). In the graph on the left, the vertical axis indicates total land area and the horizontal axis indicates total population. Circle size is proportional to the number of coverage stations required for a 6-minute average travel time in each city (which also is indicated numerically). Detroit and Phoenix have populations above 3.5 million, but Detroit covers a larger land area and therefore requires 48 coverage stations compared with Phoenix's 35. Pittsburgh and Sacramento have similar populations, but Pittsburgh requires roughly three times more stations. Poughkeepsie requires twice as many stations as Des Moines. The right side of Figure 8 clarifies the coverage relationships, revealing a roughly linear correlation between station density (stations per 100 square miles) and population density, as derived in Nicholas, Handy, and Sperling (2004). The cities with lower population densities require higher station densities to achieve comparable coverage.
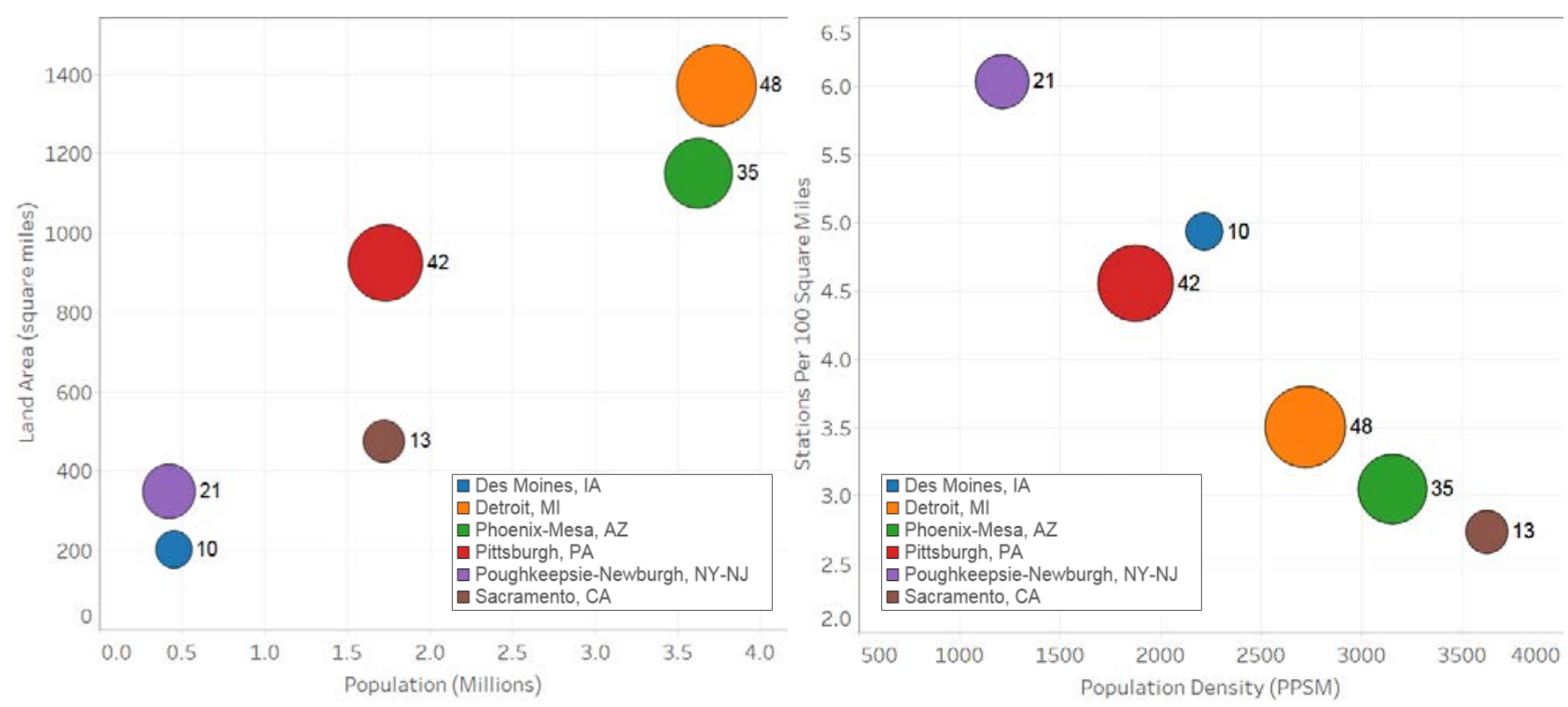

Figure 8. Example of coverage stations required (circle size and labels) for pairs of urban areas with similar populations but distinct population densities

SERA uses the basic correlation demonstrated in Figure 8, inspired by Nicholas, Handy, and Sperling (2004), to estimate the number of coverage stations required in any major U.S. urban area. The result is the number of stations that must be installed to open up FCEV markets to early adopters in a city, cluster of cities, or a region. The order in which these urban markets should be opened - that is, when each should receive its complement of coverage stationsdepends on a number of different factors. For the scenarios developed in the recent H2USA report (Melaina, Bush et al. 2017), for example, this sequence is estimated with respect to the EAM per coverage station and EAM density required to open up that particular urban market (see Section 2.2.2).

\subsubsection{Station Sizes}

The SERA model sizes HRSs based on an algorithm that mimics empirical data from existing gasoline refueling station networks. Stations are placed strategically to maximize overall coverage within the area to which they are assigned (typically an urban area or ZIP code). The spatiotemporal station placement technique relies on three algorithms applied in sequence. First, 
the time-dependent hydrogen demand for the urban area is used to estimate the number of stations built in each year. Next, based on those station counts and an average station capacity for the year, the stations are sized according to an empirically determined capacity distribution. Finally, the stations are located stochastically within the urban area of interest. The station count algorithm is deterministic whereas the station sizing and location algorithms are stochastic.

1. Station Count (deterministic):

Let $D(t)$ be the demand for hydrogen at time $t$. The number of $\operatorname{HRSs}(N)$ at year $t+1$ is (Bush et al. 2013):

$$
\begin{gathered}
N(t+1)=N(t)+\beta N^{*}(t+1) \\
N(\mathrm{t}=0)=N_{0}
\end{gathered}
$$

where

$$
\begin{gathered}
N^{*}(t+1)=\frac{D(t+1)-D(t)}{Q_{\mathrm{ave}}(t)}, \\
\beta=\alpha^{\left(\frac{Q_{\mathrm{avc}}(t)}{Q_{\mathrm{ave}}^{\max }}-1\right)}, \\
Q_{\mathrm{ave}}(t)=\frac{D(t)}{N(t)} .
\end{gathered}
$$

Here $\alpha$ and $Q_{\mathrm{ave}}^{\max }$ are numerical constants chosen to so that the size distribution of HRSs mimics the empirical distribution of sizes of gasoline refueling stations $\left(\alpha=2.5\right.$ and $\left.Q_{\mathrm{ave}}^{\max }=8,000\right)$. This algorithm results in a small average station capacity in early years, which approaches the maximum size $Q_{\mathrm{ave}}^{\max }$ as time progresses. For each year $t, n(t)=N(t)-N(t-1)$ stations are built with capacity $C_{i}$ and location $\left(\varphi_{i}, \lambda_{i}\right)$ chosen according to the following two algorithms.

2. Station Capacity Sizing (stochastic):

Let $X_{i}$ be uniform $[0,100]$ independent, identically distributed random variables, where $i$ is the station number. The capacity of the station $i$, which is constructed at time $t$, is given by an empirical fit to the observed size-distribution of gasoline stations (Bush et al. 2013):

$$
C_{i}=\frac{264.1-8.921 X_{i}+0.1947 X_{i}^{2}-0.002187 X_{i}^{3}+0.000008948 X_{i}^{4}}{100} Q_{\mathrm{ave}}(t)
$$


This results in the station capacity distribution shown in Figure 9.

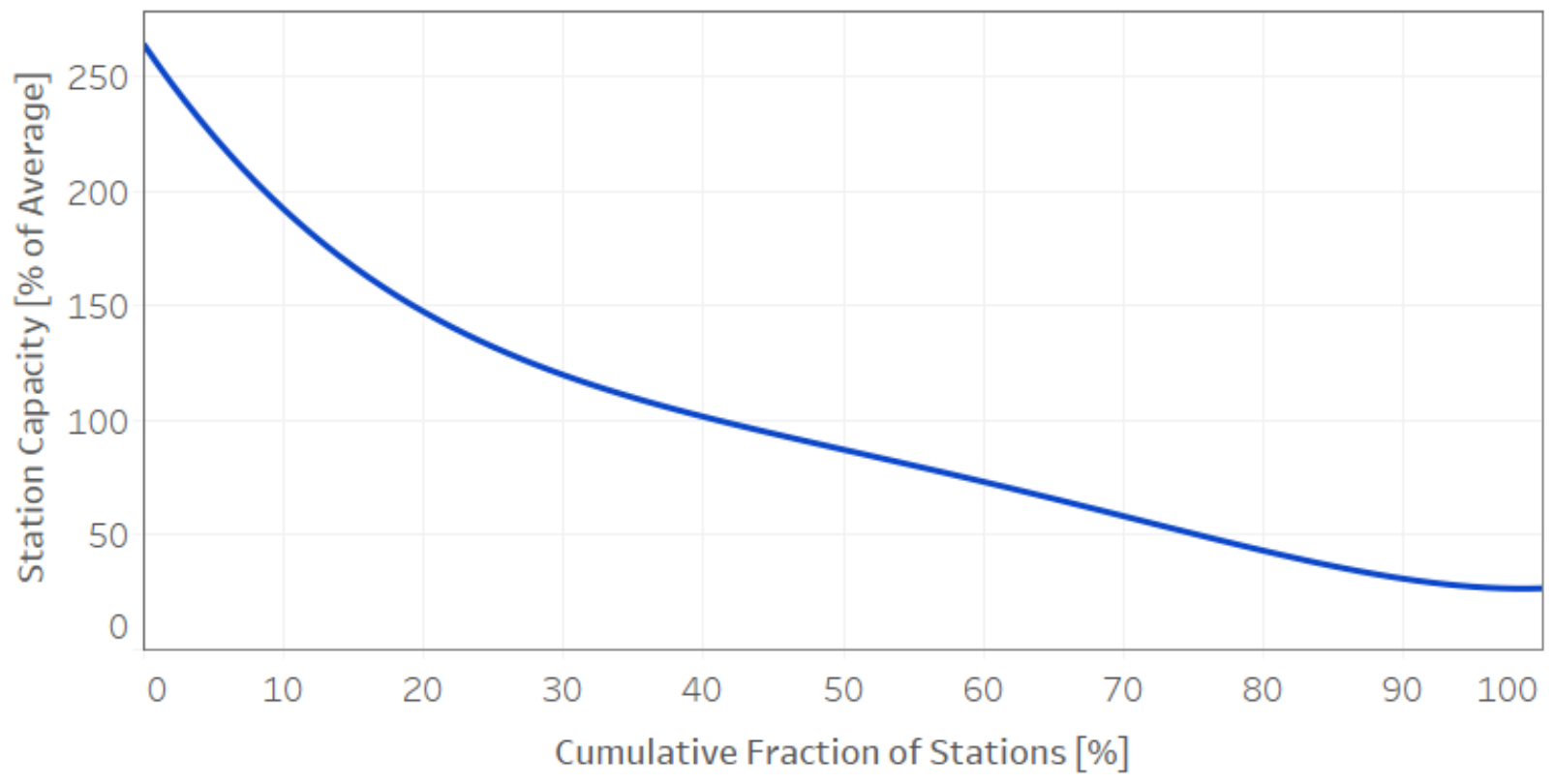

Figure 9. Generic station capacity distribution: the chart is interpreted, for example, as saying that $20 \%$ of the stations (reading on the horizontal axis) are at least $150 \%$ of the average station capacity (reading on the vertical axis)

3. Station Fine-Grid Placement (stochastic):

Although stations have been allocated to each region of interest (e.g., urban areas), there might be interest in further refining the geographical distribution of such stations at a finer grid (e.g., a $0.5 \mathrm{~km} \times 0.5 \mathrm{~km}$ grid). This problem is highly dependent on local conditions such as traffic flow, availability and cost of space, and marketing considerations, and is not explicitly addressed by the SERA model. Instead, the model stochastically locates the HRSs within each area of interest (Bush et al. 2013).

\subsubsection{Population Enabled}

A useful metric for assessing the effectiveness of a refueling network is the population that has convenient access to the network, or "population enabled." The SERA model estimates the enabled population using a distance-based-coverage algorithm that approximates the portion of a city population that has convenient access to the hydrogen refueling network. The threshold for this calculation is the number of required coverage stations: once that threshold is reached, the entire population of the city is considered to be "enabled." During the early deployment phase, when fewer hydrogen stations are deployed, the population enabled is estimated to be the share of the total population proportional to the number of HRSs deployed divided by the number of required coverage stations (i.e., in each urban area, population enabled = number of HRS / number of coverage stations). However, the number of required coverage stations is determined based on an urban area's EAM, so achieving that minimal coverage gives convenient access to the area's entire population but does not provide the refueling capacity needed to meet the demand of the entire population (i.e., while a station provides coverage to a certain area and thus 
enables access for a certain population, it does not necessarily have enough capacity to serve the entire population enabled if everyone adopted FCEVs).

\subsection{Financial Metrics}

The SERA model also computes an extensive set of financial metrics on a station-by-station basis based on exogenously assumed fuel prices, including cost of delivered hydrogen (paid by the HRS operator) and retail hydrogen price (paid by consumers). Particularly relevant for the financial performance of each HRS is the retail margin, which is the difference between the delivered hydrogen cost and retail price. Some additional financial metrics are listed below and have been used in a previous assessment of HRSs in California (McKinney et al. 2015). The full set of financial metrics is also included in the Excel spreadsheet version of the Hydrogen Financial Analysis Scenario Tool (H2FAST) model (NREL 2017).

\section{Net profit}

Net profit is a company's total earnings, calculated by subtracting the total costs of doing business (such as operating costs, depreciation, interest, and taxes) from the total revenues.

\section{Operating profit}

Operating profit is the profit earned from a firm's core business operations. This value does not include any profit earned from the firm's investments or the deductions of applicable interest and taxes owed.

\section{Gross margin}

Gross margin is a company's total sales revenue minus its cost of goods sold, divided by total sales revenue. The gross margin represents the percentage of total sales revenue that the company retains after incurring the direct costs associated with producing the goods and services it sells.

\section{Debt service coverage ratio}

The debt service coverage ratio is calculated by dividing the net operating profit by the total debt service. The total debt service includes current debt obligations (interest, principal, and lease payments due in the current year). In effect, debt service coverage ratio is a measure of the cash flow available to pay current debt obligations. 


\section{Scenario Development: Inputs and Assumptions}

This section reports the inputs and assumptions used in the SERA model to generate the national FCEV adoption scenarios and refueling infrastructure buildout reported in the 2017 H2USA national hydrogen infrastructure report (Melaina, Bush et al. 2017). Table 2 summarizes the market trends that define the scenarios: Urban Markets, State Success, and National Expansion. In each scenario, successful FCEV market growth is achieved through the coordinated rollout of vehicles and stations. All three scenarios assume strong future FCEV market growth in California followed by market expansion into other cities, states, and regions. However, the scenarios vary by the rate and geographic scope of HRS network deployment and related investments. These infrastructure investments support FCEV market growth trends that vary based on scenario design assumptions about responsiveness to consumer demand, policy drivers, and local and regional planning and coordination efforts. Differences among the scenarios provide insights into infrastructure-development trends that could result from the combined influences of policy support mechanisms, consumer demand, and successful coordination and planning among automakers, fuel providers, station owners, investors, and government agencies. The numerical inputs to the SERA model (described in Section 2) were set so that SERA's outcomes match the narrative for each scenario in Melaina et al. (2017).

Table 2. Market Trends by Scenario (from Melaina, Bush et al. 2017)

\begin{tabular}{|l|c|c|c|}
\hline Market Trend & \multicolumn{1}{|c|}{ Urban Markets } & State Success & National Expansion \\
\hline $\begin{array}{l}\text { Dominant policy } \\
\text { drivers }\end{array}$ & $\begin{array}{c}\text { Support at local and } \\
\text { municipal levels } \\
\text { combines with strong } \\
\text { early adopter demand }\end{array}$ & $\begin{array}{c}\text { ZEV mandate and } \\
\text { other support policies }\end{array}$ & $\begin{array}{c}\text { Combination of strong } \\
\text { local, state, and national } \\
\text { policies }\end{array}$ \\
\hline $\begin{array}{l}\text { Coordination and } \\
\text { planning }\end{array}$ & $\begin{array}{c}\text { Investments focused } \\
\text { on most promising } \\
\text { metropolitan markets }\end{array}$ & $\begin{array}{c}\text { Strong coordination } \\
\text { across ZEV mandate } \\
\text { states }\end{array}$ & $\begin{array}{c}\text { Strong coordination and } \\
\text { planning across all } \\
\text { regions }\end{array}$ \\
\hline Consumer adoption & $\begin{array}{c}\text { High concentrations of } \\
\text { early adopters guide } \\
\text { market development }\end{array}$ & $\begin{array}{c}\text { FCEV adoption } \\
\text { primarily driven by } \\
\text { ZEV mandate }\end{array}$ & $\begin{array}{c}\text { Adoption moves quickly } \\
\text { from concentrated early } \\
\text { adopters and ZEV } \\
\text { mandate states to broad } \\
\text { megaregion markets }\end{array}$ \\
\hline $\begin{array}{l}\text { HRS network } \\
\text { expansion }\end{array}$ & $\begin{array}{c}\text { Gradual expansion } \\
\text { from promising urban } \\
\text { markets to nearby } \\
\text { cities }\end{array}$ & $\begin{array}{c}\text { Focus on ZEV } \\
\text { mandate states, with } \\
\text { gradual expansion into } \\
\text { additional markets }\end{array}$ & $\begin{array}{c}\text { Strong policy drivers and } \\
\text { coordination reduce } \\
\text { investment risks, allowing } \\
\text { rapid network expansion }\end{array}$ \\
\hline \multicolumn{2}{|c|}{ FCEV Sales per Year (millions) and Market Share (\%) of Total Sales in Urban Areas in 2050 }
\end{tabular}

a Total sales are based on EIA (2017). Future vehicle sale projections are taken from the EIA Annual Energy Outlook. Within each census division, sales are allocated to different urban areas based on the proportion of current vehicle stock, from IHS automotive data. For example, if Arvin, California, has 1\% of the current vehicles in the Pacific census division, it is assumed that $1 \%$ of the new vehicle sales in that division will occur in Arvin, California. 
Station quantity, location, and deployment schedule depend on assumptions about initial station coverage requirements for early FCEV adopters, average station sizes, the geographic extent of urban markets, consumer demographics, and rates of FCEV market growth. Each of the three scenarios resolves these interrelated factors through internally consistent simulations of FCEV adoption and HRS network-expansion dynamics, drawing on empirical trends and updated plans from recent studies. The result is a set of complete national HRS network simulations, with temporally and spatially resolved HRS locations, sizes, and installation years as FCEV market shares increase over time and across different U.S. regions.

\subsection{Vehicle Stock and Performance}

In these scenarios, FCEVs become available starting from 2015 in California and gradually expand to other markets.

\subsubsection{Vehicle Stock}

A logistic function is used to project the sales of FCEVs over time based on initial sales estimates (in line with vehicles already sold and sales projections in California [CARB 2017a]) and longer-term sales projections nationally. The following is the general logistic equation:

$$
S_{t}=\frac{M}{\left[1+\left(\frac{M}{S_{t_{n}}}-1\right) e^{-r M\left(\beta t-t_{0}\right)}\right]}
$$

where

$S_{t}=$ FCEV market share as percent of annual LDV sales in year $t$

$S_{t o}=$ Beginning FCEV market share in year $t_{o}$

$M=$ Maximum market share over time (as $t$ becomes large)

$r=$ Rate of market share growth $(\%$ per year $)$

$\beta=$ Time constant.

The logistic function constants are very sensitive to initial conditions. Initial national and California market shares (percent of LDV sales as FCEVs) are estimated as follows:

$$
S_{t_{o}}=\frac{n_{F C E V, t_{o}}}{n_{L D V, t_{o}}}
$$

where

$n_{F C E V, t o}=$ Number of FCEVs sold in year $t_{o}$

$n_{L D V, t o}=$ Number of LDVs sold in year $t_{o}$. 
Figure 10 shows assumed vehicle sales in the three scenarios considered. Sales in the Urban Markets and State Success scenarios reach approximately 3 million and 5 million FCEVs per year by 2050 , respectively. The sales trajectory in Urban Markets is approaching saturation near 2050, while sales in State Success are still growing strongly by 2050. Sales in the National Expansion scenario are at about 8 million FCEVs per year by 2050, roughly half of all LDV sales, and still experiencing relatively strong growth. These FCEV market growth trends in California underpin the market growth trends in other ZEV states as well as the rest of the country. As a reminder, the Urban Markets scenario focuses on market growth in urban areas with high early adopter density, the State Success scenario assumes growth trends are more concentrated in ZEV states, and the National Expansion scenario growth is distributed more generally across all LDV markets.

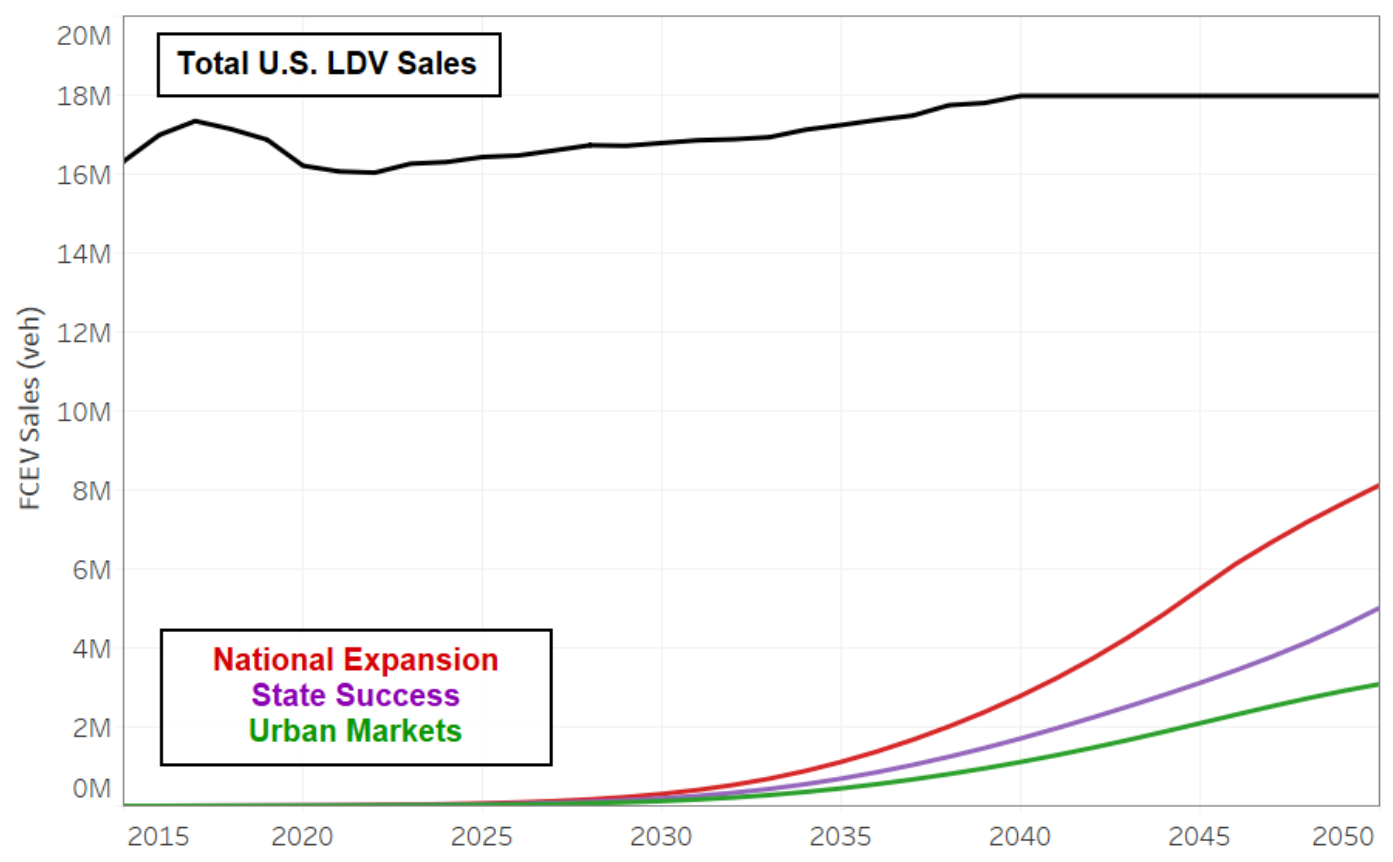

Figure 10. FCEV sales by scenario compared with total U.S. LDV sales

Initial (2016-2022) California sales in the State Success scenario, as shown in Figure 11, lead to an FCEV stock (vehicles on the road) that matches estimates from recent automaker surveys conducted by the California Air Resources Board (CARB 2017a). 


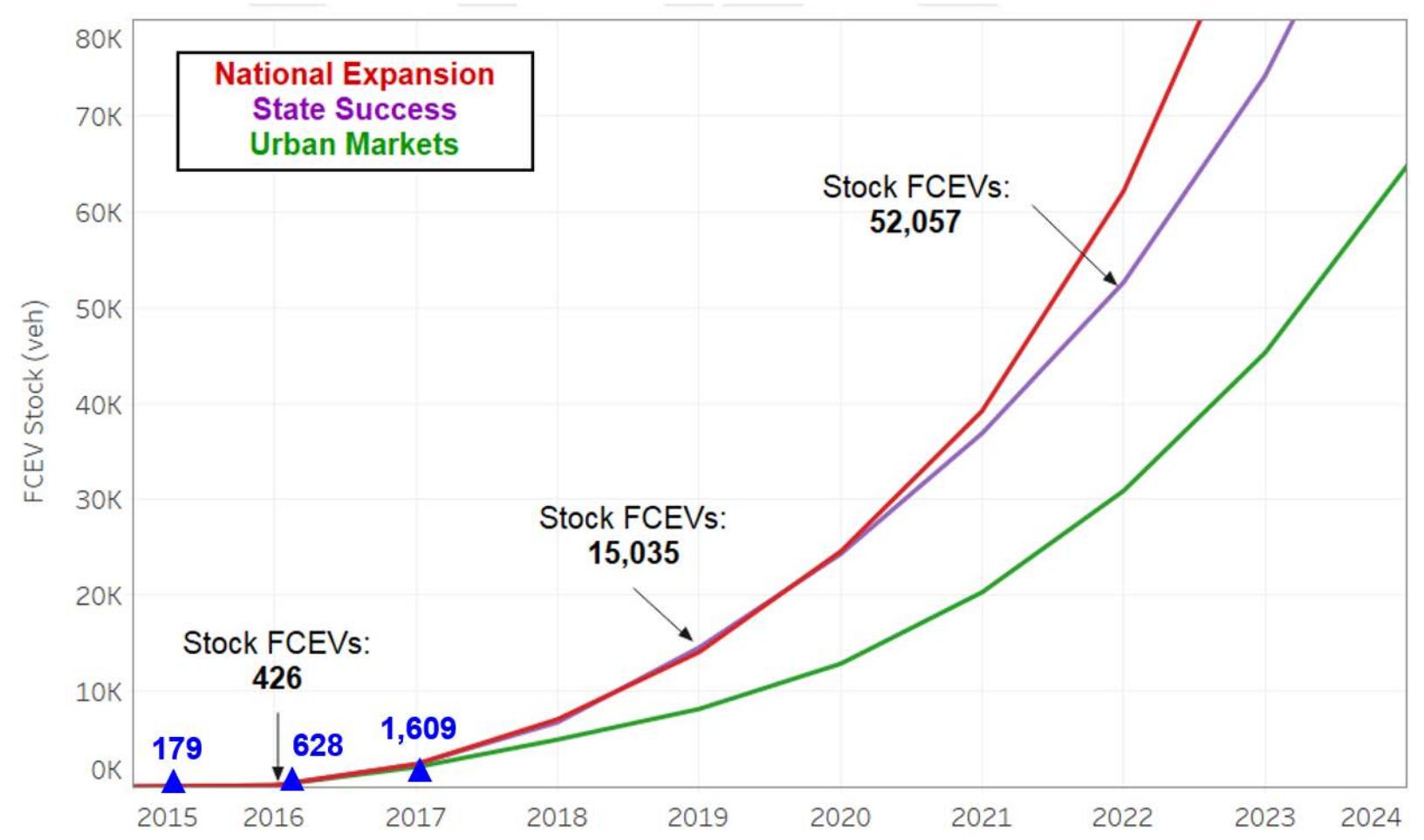

Figure 11. Early California FCEV stock by scenario compared with Assembly Bill 8 survey values (blue triangles) (CARB 2017a)

A more detailed depiction of these sales projections is shown by region in Figure 12. The top set of panels indicates that, within the Early Markets period (2016-2025), FCEV sales and leases in the Urban Markets and State Success scenarios are significantly lower than those in the National Expansion scenario. Most of the sales are into California markets in each scenario, with the State Success scenario having minimal sales into markets in the rest of the country (ROC). The middle set of panels shows sales for the Expansion period (2016-2035) and has a different scale on the vertical axis: up to 1.5 million FCEVs per year, compared with 100,000 FCEVs per year in the Early Markets period. Sales into ROC markets are still minimal in the State Success scenario, but ROC sales begin stronger growth in the National Expansion scenario. California sales still dominate the FCEV market by 2035, with significant sales in other ZEV states as well. The bottom set of panels shows FCEV sales in the Long-term Growth period (2016-2050), adjusting to a scale of up to 10 million FCEVs per year on the vertical axis. By 2050, FCEV sales in State Success are nearly double those in Urban Markets, and sales in National Expansion are nearly double those in State Success. These sales are roughly equally divided among the three regions in the Urban Markets scenario, while the ZEV states play a larger role in the State Success scenario, and the ROC region becomes the dominant market in the National Expansion scenario. 

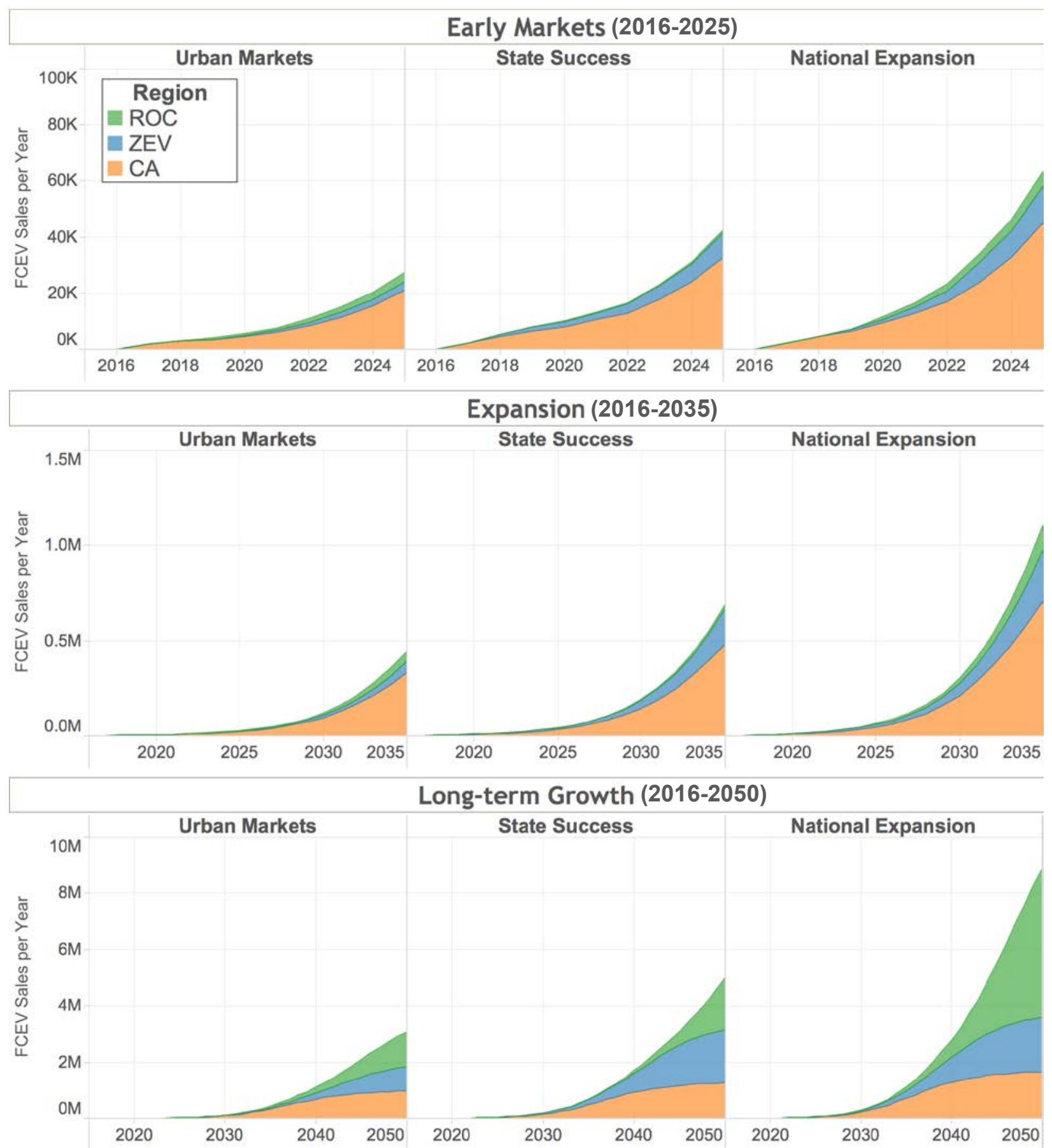

Figure 12. Breakdown of FCEV sales by period and region for the Urban Markets, State Success, and National Expansion scenarios

Note: The scale of the vertical and horizontal axes changes between each of the three periods.

Although the National Expansion scenario exhibits relatively rapid FCEV sales growth, it is still more conservative than the FCEV success scenario developed in a 2013 report from the National Academy of Sciences, which assumes favorable market and policy conditions (NRC 2013). In that study, annual sales of 10 million FCEVs are achieved through aggressive market growth 
between 2015 and 2036, approximately 15 years earlier than the National Expansion scenario sales trend indicated in Figure 12.

\subsubsection{Vehicle Performance Assumptions}

Figure 13 shows the FCEV fuel economy evolution over time assumed in these scenarios. Fuel economy values in the early years (2015-2020) are taken from the California Air Resources Board (CARB 2017a). Long-term fuel economy values match projections from the California Air Resources Board Vision 2.1 model (CARB 2017b).

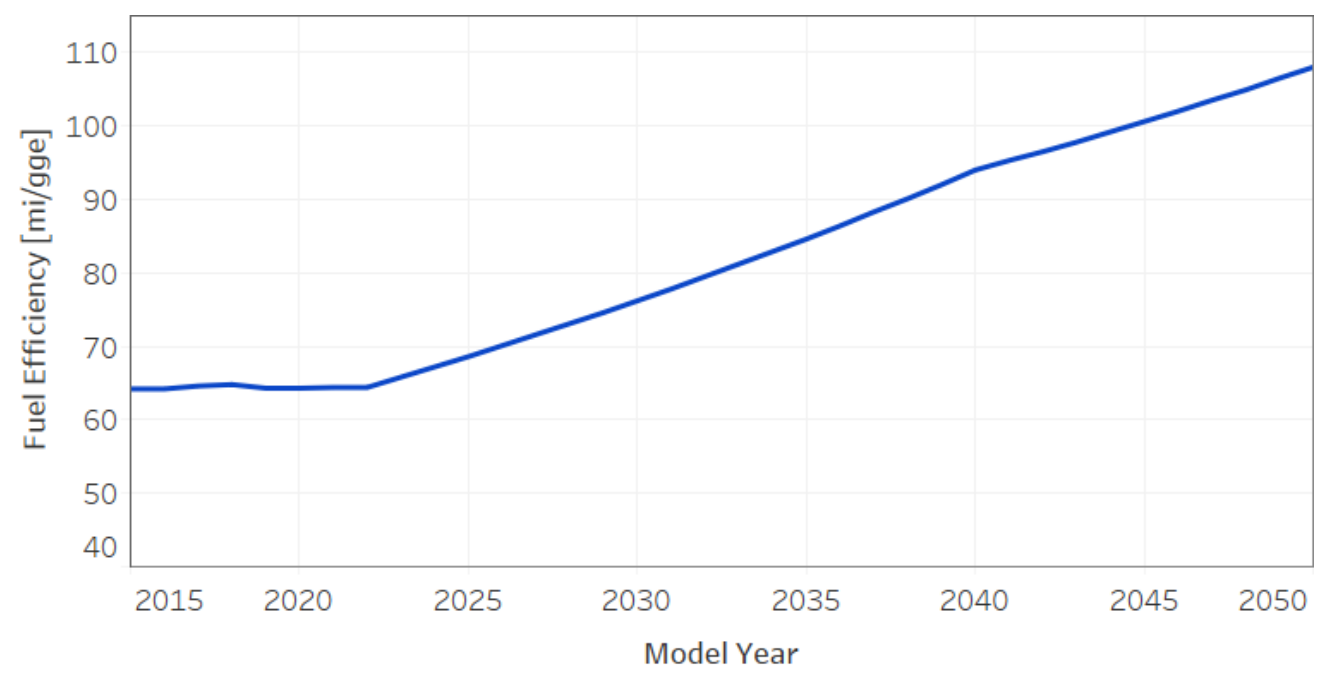

Figure 13. FCEV fuel economy assumptions

FCEVs in developed hydrogen markets are assumed to be driven similarly to conventional gasoline vehicles. Figure 14 shows the assumed annual mileage traveled by each vehicle, capturing the decreased average vehicle use as each vehicle ages (CARB 2017b). However, when FCEVs are first introduced in an urban area, they are assumed to cover only $50 \%$ of the miles reported in Figure 14 for the first 3 years of operation based upon empirical data from FCEVs and HRSs deployed in California (Baronas et al. 2017). It is assumed that this effect declines as HRS networks become more extensive. This VMT reduction assumption (relative to conventional vehicles) declines by $10 \%$ every year after FCEVs are first introduced in a new market, reaching parity with conventional gasoline vehicles in terms of miles driven annually after 5 years. FCEVs are assumed to retire at a rate identical to conventional vehicles, as shown in the function illustrated in Figure 15 (ANL 2017). 


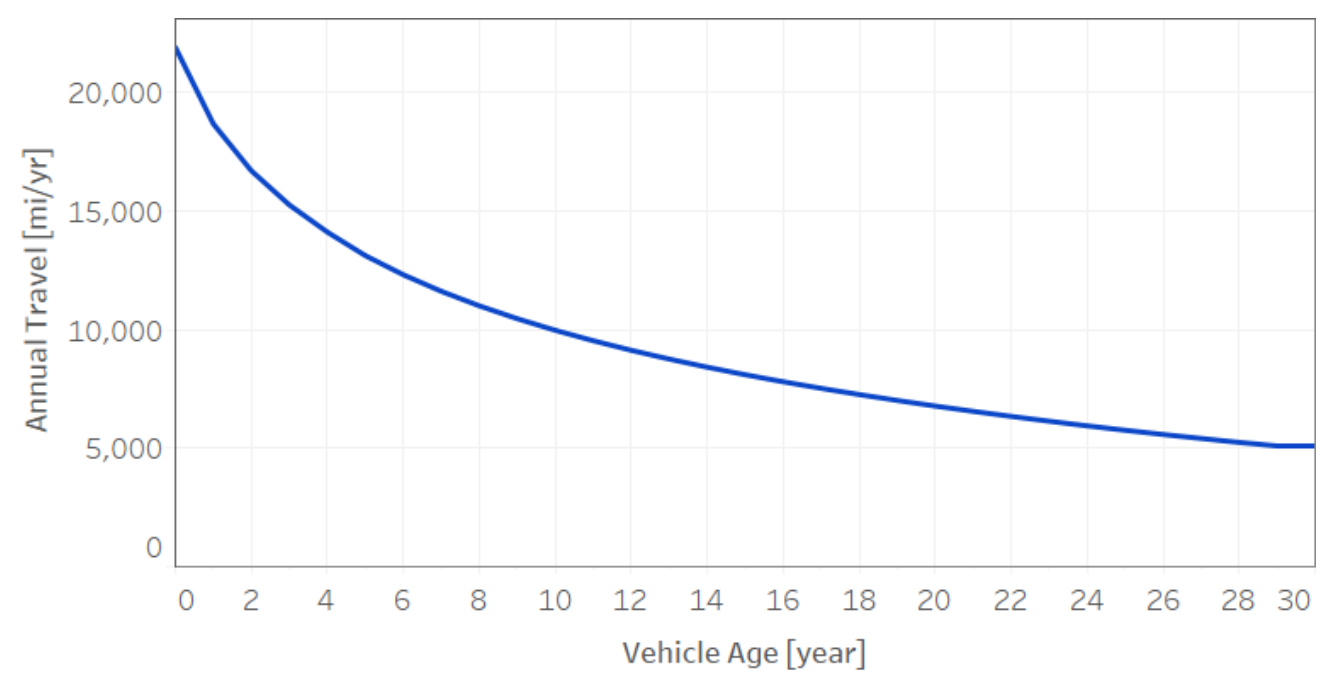

Figure 14. Assumed annual miles traveled as a function of vehicle age

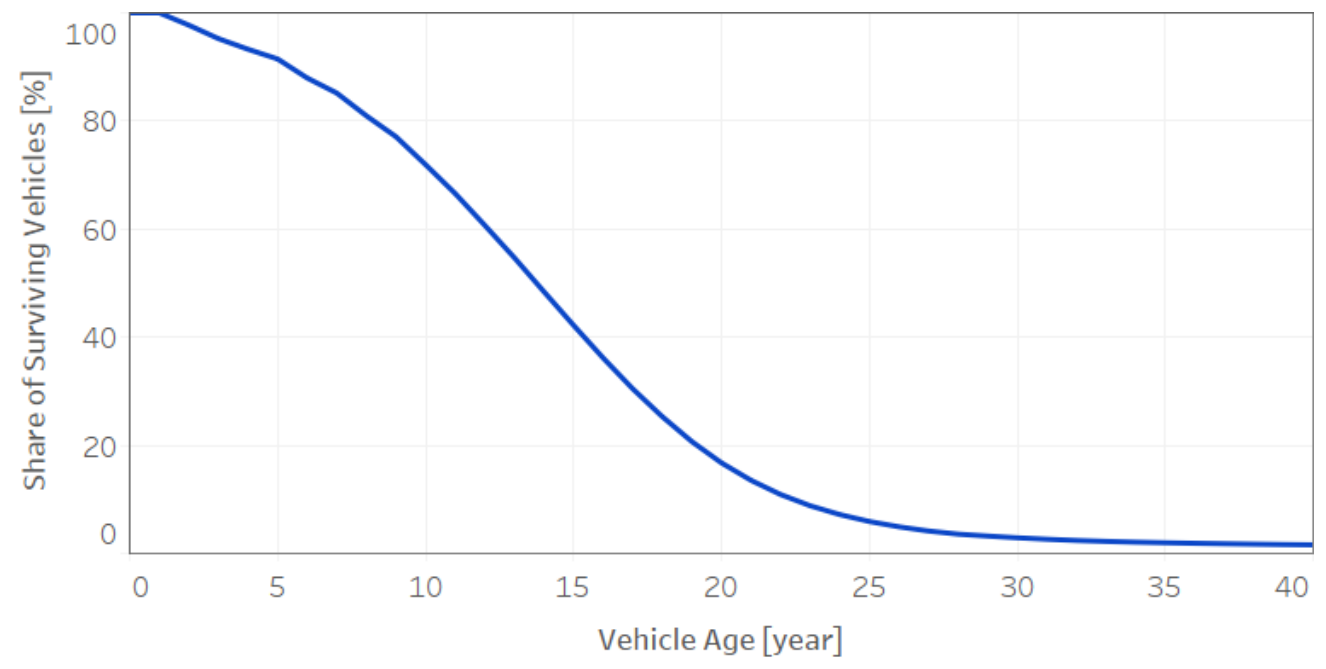

Figure 15. Assumed FCEV survival function

\subsection{Hydrogen Demand}

The annual demand of hydrogen to satisfy FCEV demand in each region is computed in SERA based on vehicle stock and performance assumptions. Given the hydrogen demand in each region (typically a city), SERA then computes how many refueling stations are required to maximize coverage as well as the size of the stations deployed.

The rollout of FCEVs and HRS networks in ZEV and non-ZEV state urban areas and megaregions is assumed to follow patterns similar to the planned rollout in California, although delayed in time and adjusted for variations in consumer demographics (the numerical inputs to SERA were set to create this mimicry). Three main dynamics influence infrastructure supply simulations: (1) the influence of early adopters, (2) the requirement for coverage stations to open urban markets to large FCEV sales volumes, and (3) the sequence in which additional urban markets are opened over time by establishing a sufficient number of coverage stations. 
Early adopters are critical to initial market development in all three scenarios. However, the scenarios differ in the extent to which network development patterns depend on the influence of early adopters compared with the other market drivers summarized in Table 2 . The coverage stations must enable most early adopters to live within a 6-minute drive of a station (Melaina, Bremson, and Solo 2012; Nicholas, Handy, and Sperling 2004; Melaina et al. 2013; CaFCP 2014; Brown et al. 2015). This approach tends to result in one or more stations being clustered in neighborhoods with high concentrations of early adopters. Additional stations provide refueling availability across the larger urban area, resulting in a network that satisfies the refueling needs of most early adopters.

\subsubsection{Urban Market Sequencing}

Urban areas with the greatest EAM density (EAM per square mile) and EAM per coverage station are the first markets to have coverage stations installed and FCEVs sold in significant volumes. The metrics behind this sequencing are shown in Figure 5, and the introduction years across the three scenarios are summarized in Figure 16 for a sample of urban areas.

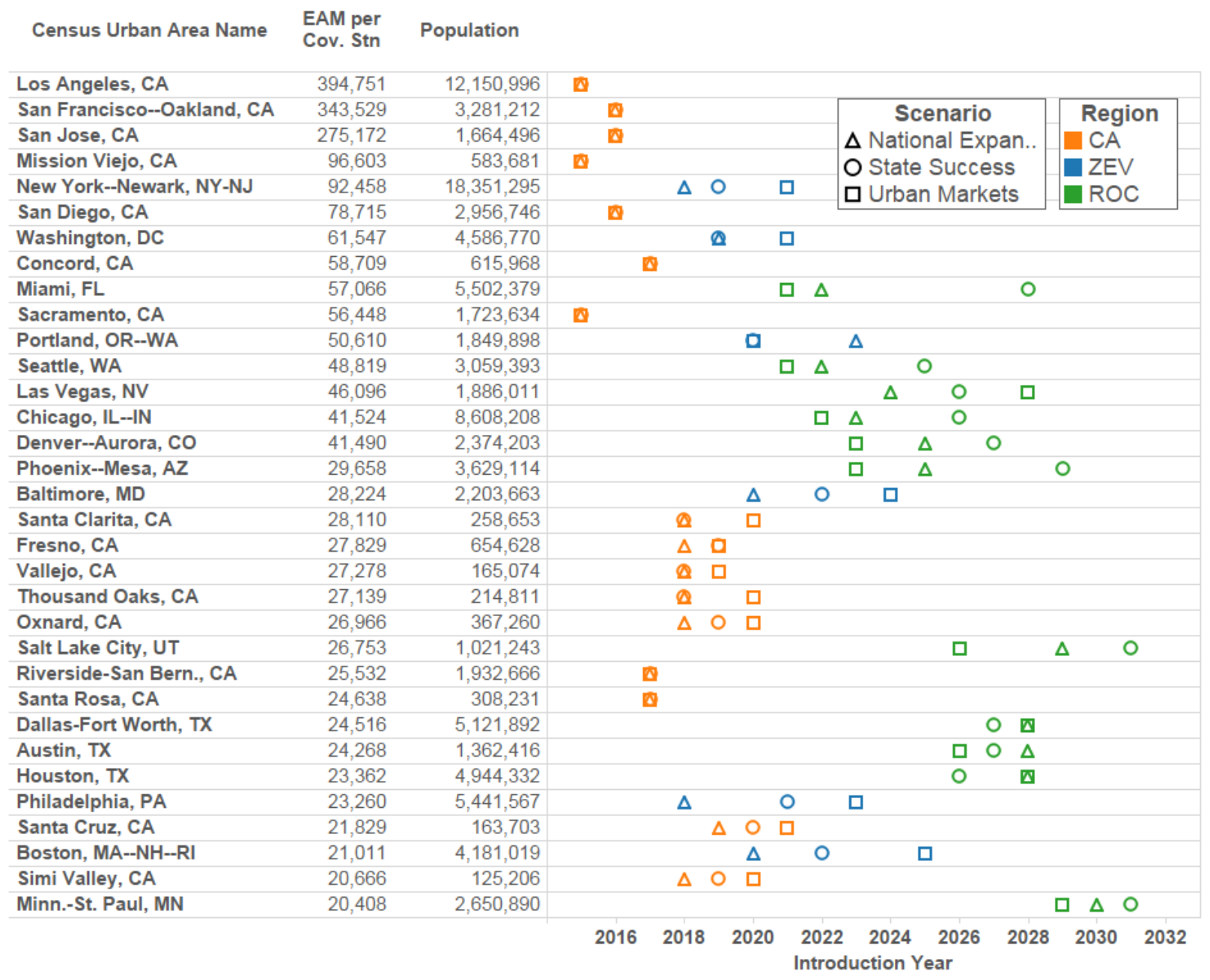

Figure 16. HRS introduction year by scenario 
Station introduction years range from 2015-2016 for a few urban areas in California that received the first FCEVs, to past 2040 for the latest urban area introductions. The expansion outside California is determined by the overall FCEV sales and the market drivers summarized in Table 2. For example, stations are introduced in Chicago (a Tier 3 urban area) in 2022 in the Urban Markets scenario because of that city's moderately high concentration of early adopters. In the National Expansion scenario, FCEV deployment is more coordinated and dispersed around Tier 1 urban areas, and thus stations are introduced in Chicago 1 year later, in 2023. In the State Success scenario, FCEV deployment is driven by the ZEV mandate, and stations are not introduced in Chicago (which is not in a ZEV state) until 2026. New York, which is a Tier 2 urban area in a ZEV state, sees the first station introduction in the National Expansion scenario (2018), followed closely by introductions in the State Success (2019) and Urban Markets (2021) scenarios.

\subsubsection{Expanding Local Networks: Clustered vs. Dispersed Local Demand}

Although metrics such as coverage station requirements and EAM densities can help prioritize investments in specific urban markets, it is likely that local and regional demand patterns will evolve across networks of urban areas rather than discrete urban demand "islands." The expansion of station networks across geographic trade areas and into smaller, nearby cities is therefore another important infrastructure expansion trend. This trend is captured in the scenarios by assuming earlier introduction years for small cities in close proximity to large urban areas. By comparison, small cities with similar market potential (e.g., relatively high EAM to coverage station ratios) that are not close to large urban areas have later introduction years. Highly clustered demand results in a more concentrated consumer base within large urban areas, while more dispersed urban demand results in more rapid expansion of networks into smaller cities in close proximity to larger urban centers. Assuming some balance between clustered vs. dispersed demand adds realism to the national scenarios, allowing for an explicit representation of how HRS networks may expand in response to local demand patterns.

Local network expansion dynamics can be explained in terms of two trends: (1) adoption trends across market segments within a given urban area (see Figure 3), and (2) the ease of expanding station networks outward from larger urban areas into nearby smaller urban areas. This responsiveness to local demand patterns can influence network economics and financial risk. If market growth is concentrated within a limited geographic area, fewer and larger stations can be relied upon at higher utilization levels to serve a larger consumer base. This trend would be reinforced by the neighborhood effect as adoption moves across select neighborhoods within a given urban area, as well as by relatively high marginal costs that inhibit expanding infrastructure into smaller, nearby cities. Conversely, if continued market growth requires more rapid expansion of urban networks into new geographic trade areas, a larger number of smaller stations may be required, reducing station economies of scale and potentially reducing average network utilization levels. This trend would be more prevalent if early adopter markets are relatively shallow within a given urban area, with new adoption occurring within innovator and early adopter market segments in smaller, nearby urban areas. Lower marginal costs of network geographic expansion would also reinforce this trend.

Highly clustered network growth, if sustained by concentrated early adopter demand in large urban areas, will lead to lower hydrogen prices and accelerated returns to investors. However, some degree of local network expansion will be required to maintain strong market growth both 
regionally and nationally. ${ }^{6}$ The causal mechanisms between local demand patterns and local supply decisions are not explicitly modeled in terms of optimal market outcomes, but the national scenarios do capture a balance between clustered and dispersed local demand trends.

Figure 17 depicts an example of how extremes in these two local demand trends could influence station introduction years for urban areas. A local clustering parameter is varied between $90 \%$ and $20 \%$ to achieve variations in urban area station introduction years, which are shown on a color scale ranging from early introductions between 2015 and 2033 (red, orange, and yellow) to later introductions between 2033 and 2050 (light to dark green). Circle size indicates the total number of LDVs within each urban area. The maps on the left side of Figure 17 show introduction years assuming highly clustered demand within urban areas, with proximity to larger urban areas having little influence on the introduction years of smaller urban areas. In contrast, the maps on the right side of Figure 17, representing highly dispersed local demand, have earlier introduction years for smaller cities in close proximity to larger cities. Note that this local clustering trend is much less apparent in the national map views at the top of Figure 17.

For example, with highly clustered demand (higher local clustering parameter values) in southern California (Figure 17, left), HRSs are introduced in smaller urban areas just outside the Los Angeles urban area relatively late (colored orange, yellow, and green), but this shifts to early years (red or orange) with highly dispersed local demand (Figure 17, right). The same effect is shown for Northeast urban areas, with HRS introduction for smaller cities near New York shifting from later years with highly clustered local demand (green in the left map) to earlier years with highly dispersed local demand (yellow in the right map).

\footnotetext{
${ }^{6}$ Moving beyond urban markets, hydrogen supply networks must eventually expand into rural areas to achieve very large regional and national market shares, although this trend is not addressed in the current scenarios.
} 


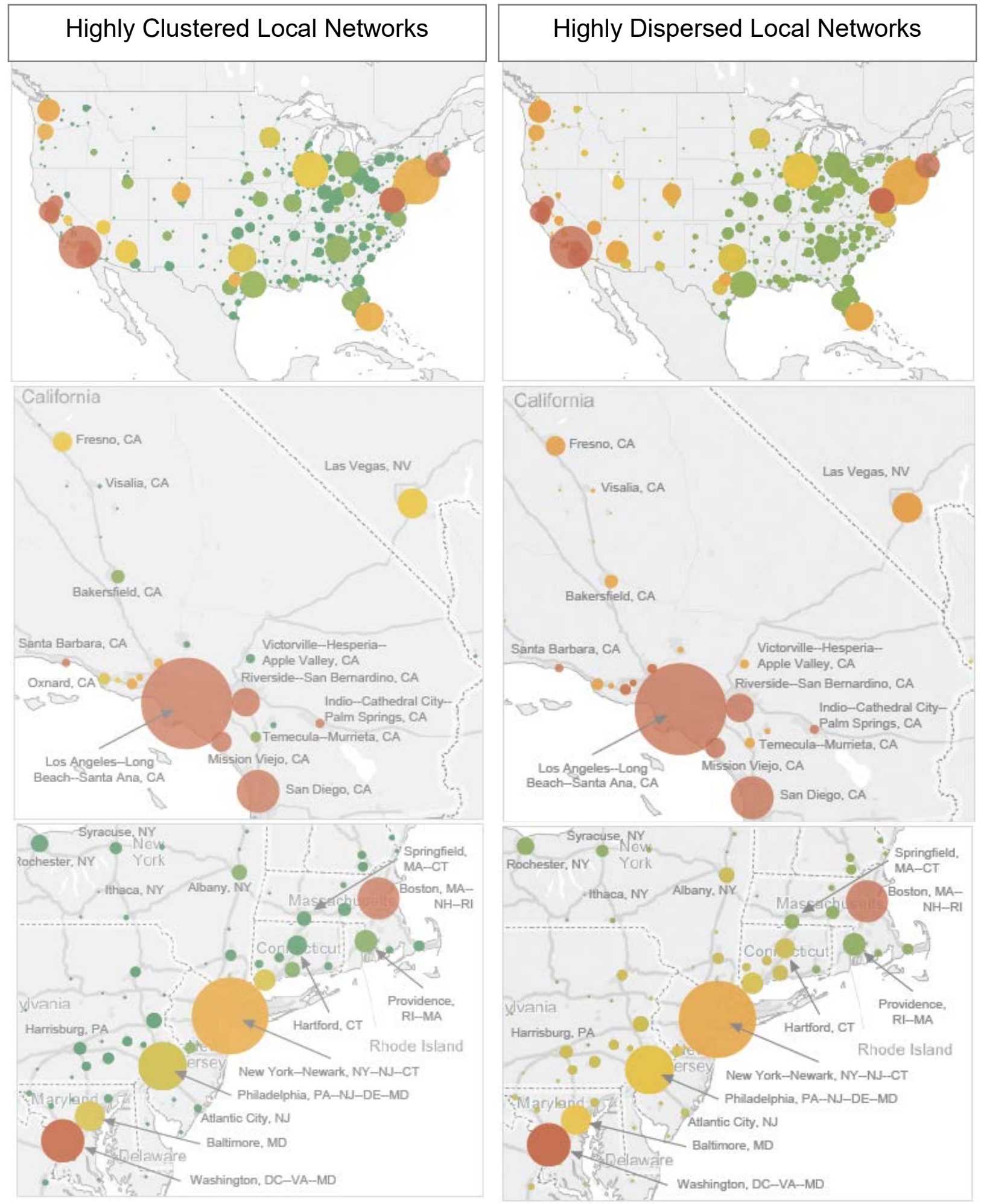

Figure 17. Examples of highly clustered and highly dispersed local networks and resulting HRS introduction years for urban areas

The color scale ranges from red, orange, and yellow for early introductions (2015-2033) to light to dark green for later introductions (2033-2050). Circle size indicates the total number of FCEVs within each urban area. 


\subsubsection{Regional Market Expansion}

Station networks must also expand at a regional level. This level of expansion involves network effects between major urban areas and along corridors linking regions and clusters of cities into megaregions as well as in response to the influence of state policies and early adopter prevalence. Factors that must be considered include proximity of promising urban areas, the distribution of early adopters by state, and the density of travel along interstate and other corridors. A particular focus of regional expansion in the national scenarios is the rate at which FCEV markets expand outside California into other ZEV states, and then expand into ROC. Although market expansion trends are resolved at the urban area and station level in all scenarios, simple regional trends are discussed in terms of the California, non-ZEV state, and ROC levels, acknowledging the role of the ZEV mandate as a major driver for FCEV market growth, especially in the State Success scenario.

\subsection{Station Attributes}

HRS deployment in the SERA model starts with small stations ( $\sim 350 \mathrm{~kg} /$ day of total capacity) and evolves over time to large stations $(>1,000 \mathrm{~kg} /$ day $)$ that exploit economies of scale. The HRS costs are based on the Hydrogen Station Capital Cost Calculator (HSCC), which accounts for cost reductions that could be achieved over time owing to accumulated experience as additional stations are installed, and the economies of scale associated with higher-capacity stations (Melaina and Penev 2013). Results from the HSCC do not distinguish between stations of different hydrogen production or delivery types. Instead, the cost estimates and cost-reduction trends apply generally to hydrogen stations of various types (Melaina and Penev 2013). The HSCC capital cost function is:

$$
C^{\prime}=C^{o}\left(\frac{Q^{\prime}}{Q^{o}}\right)^{\alpha}\left(\frac{V^{\prime}}{V^{o}}\right)^{\beta}
$$

where

$C^{\prime}=$ station capital cost $(\$ /$ station $)$

$C^{o}=$ base station capital cost $(\$ /$ station $)\left(C^{o} \mathrm{HSCC}=\$ 2.80\right.$ million $)$

$Q^{\prime}=$ station capacity $(\mathrm{kg} /$ day $)$

$Q^{o}=$ base station capacity $(\mathrm{kg} / \mathrm{day})\left(Q^{o} \mathrm{HSCC}=450 \mathrm{~kg} / \mathrm{day}\right)$

$V^{\prime}=$ cumulative capacity $(\mathrm{kg} /$ day $)$

$V^{o}=$ cumulative capacity at cost status of base station $(\mathrm{kg} /$ day $)\left(V^{o} \mathrm{HSCC}=25,000 \mathrm{~kg} /\right.$ day $)$

$\alpha=$ scaling factor $(\alpha \mathrm{HSCC}=0.707)$

$\beta=$ learning factor $(\beta \mathrm{HSCC}=-0.106)$.

Figure 18 shows the HRS nominal capital costs predicted by the HSCC equation for various capacities over time. It also shows when stations of various sizes are expected to come online. 


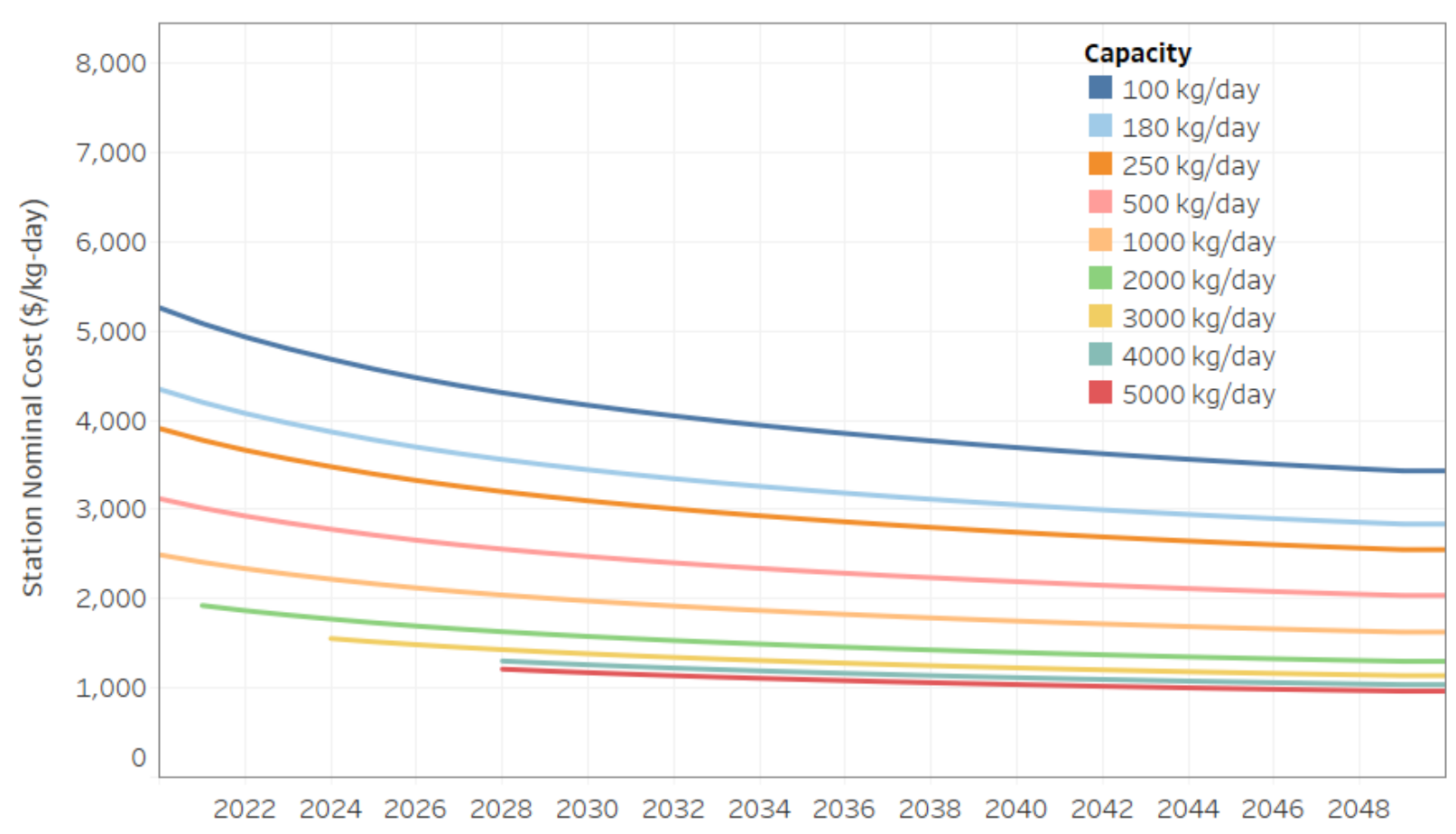

Figure 18. HRS cost as a function of capacity and time

Once the coverage stations have been constructed (see Section 2.3.1) over approximately the first 3 years of FCEV adoption in the urban area, new HRSs are built according to the algorithm in Section 2.3.2, which determines both the number and capacities of new stations and which has been tuned so that an asymptotic utilization in the $70 \%-80 \%$ range is reached after $5-10$ years. Thus, in each year the new stations have a capacity distribution that varies according to Figure 9, but with a gradually increasing average capacity that results in growing station size, all the while avoiding oversaturation of station utilization. Stations are assumed to be maintained to extend their life indefinitely.

The average size of new stations constructed depends on the level of hydrogen demand and the EAM density (as a proxy for FCEV density). Figure 19 shows the dependence of new station size on normalized demand for Los Angeles and Atlanta. Los Angeles has a high EAM density relative to its demand, whereas Atlanta has a low EAM density relative to its demand. For a higher density of early adopters, the average station size should be larger because more consumers will have access to each station. Figure 19 demonstrates that, for a constant demand, increasing the EAM density leads to an increase in station size. Over time, the stations reach a maximum average new station capacity because the rate of increase in demand begins to slow. 


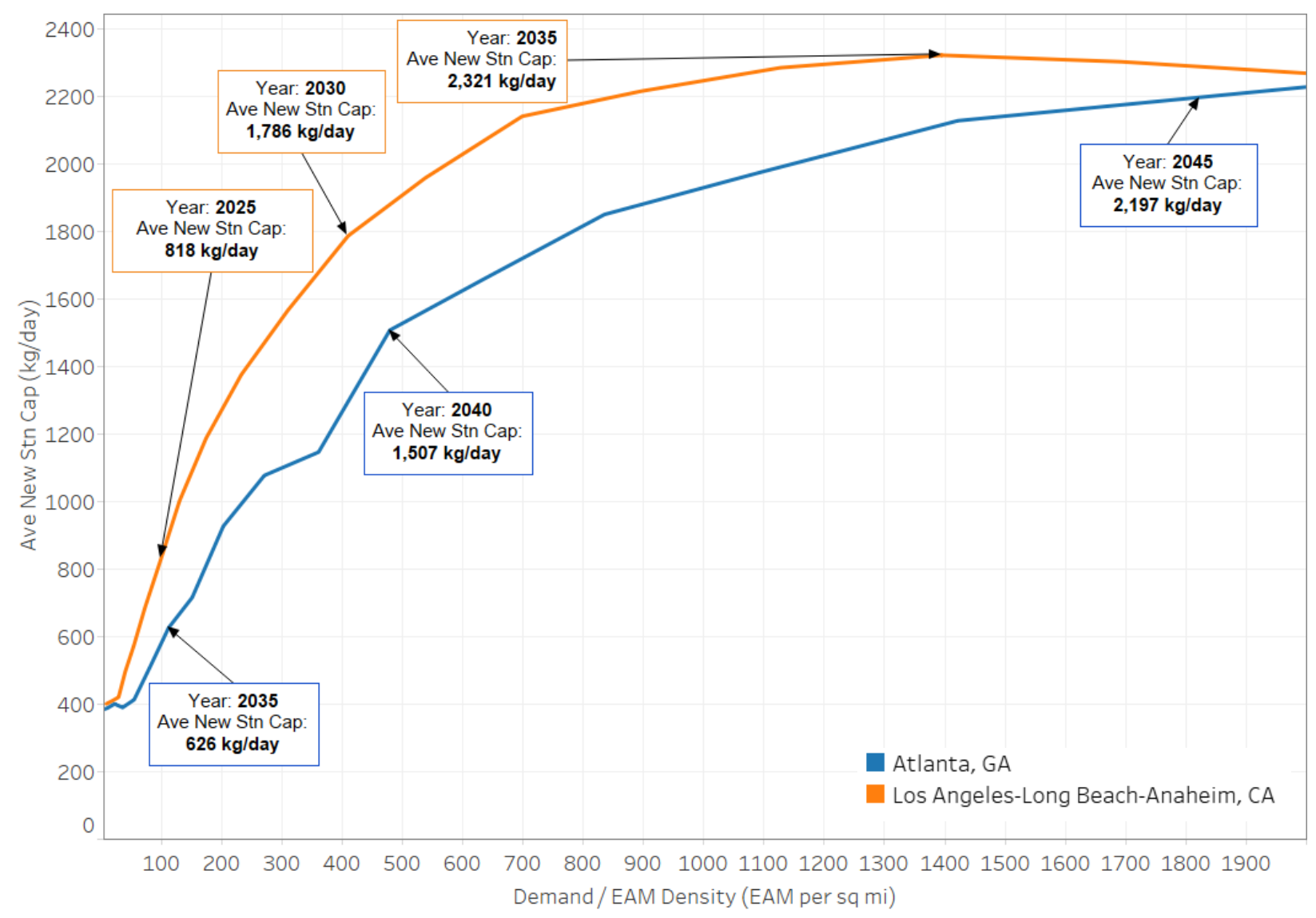

Figure 19. Average new station capacity versus normalized demand density based on EAM 


\section{Results from the H2USA National Scenarios}

This section illustrates a few example results of the three scenarios described in Section 3 and featured in the 2017 H2USA national hydrogen infrastructure report (Melaina, Bush et al. 2017) to illustrate results of the demand side of the SERA model.

\subsection{FCEV Stock}

The total FCEV stocks and HRSs installed are shown by scenario in Figure 20 for three time periods $(2025,2035$, and 2050), each represented by a panel with FCEV stock in the upper bar charts and total stations in the lower bar charts (based on the assumptions reported in Section 3). The left, middle, and right panels show results at the end of 2025, 2035, and 2050, respectively. The magnitude and geographic distribution of FCEV stocks and HRS network expansion vary among the three scenarios. Each scenario begins with highest growth in California, followed by greater or lesser expansion into the ZEV state and ROC markets. The Urban Markets scenario expands into ROC and ZEV large metropolitan areas early, with significant growth at the end of 2025 and 2035 but relatively limited total growth nationally by 2050 . The State Success scenario involves strong early growth in ZEV markets followed by delayed growth in ROC markets. The National Expansion scenario involves rapid growth in all three regions, reaching the greatest number of stations and FCEVs by 2050. These scenarios are not predictions of future market outcomes. Instead, they are intended to stimulate discussions about HRS network requirements and provide insights into how those networks might coevolve with a growing national FCEV market.
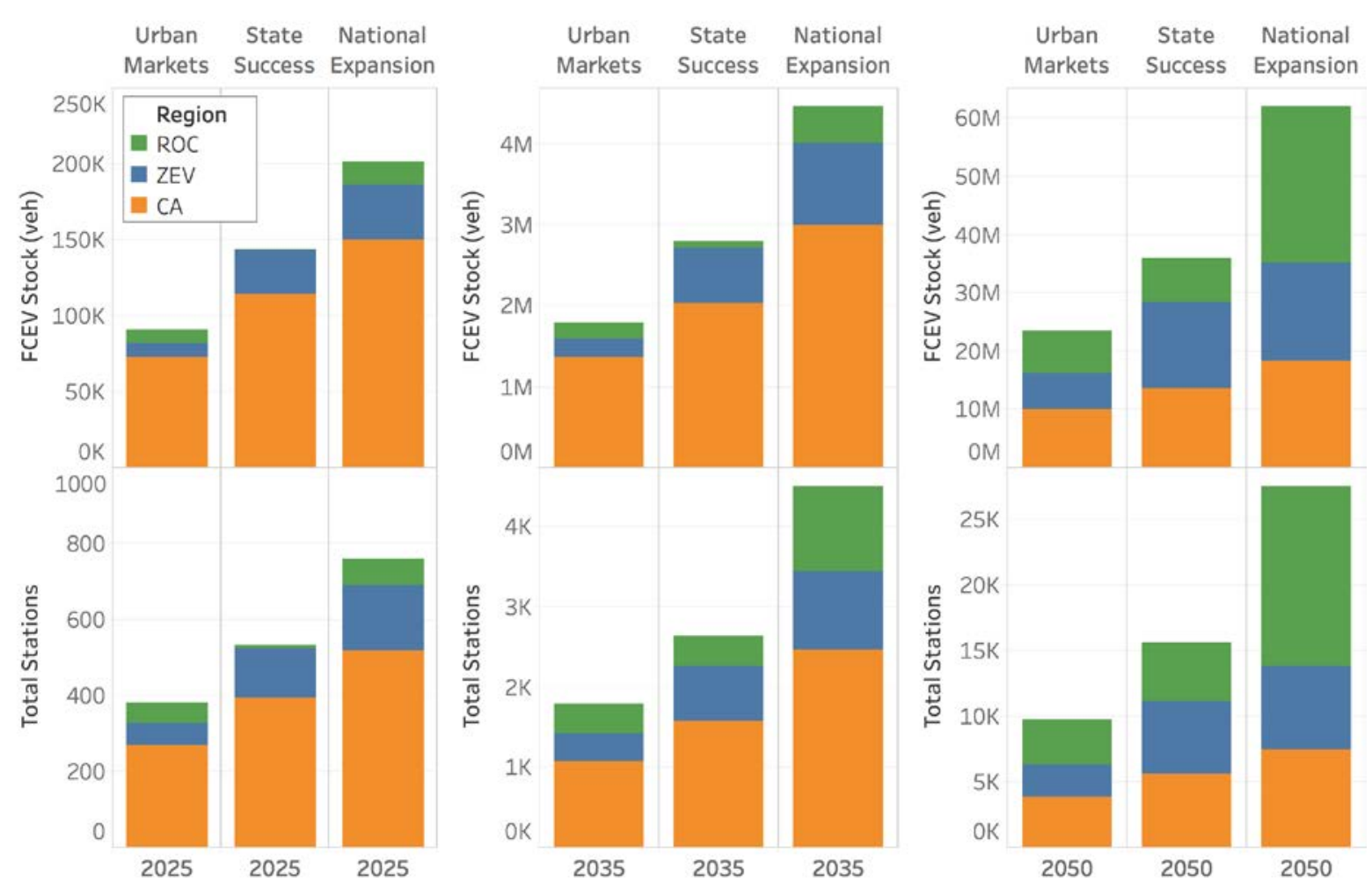

Figure 20. Number of FCEVs on the road and total HRSs by scenario and region

Note: The scale of the vertical axis changes between each of the three periods. 


\subsection{Hydrogen Demand Spatial Resolution}

The figures below detail HRS deployment over time for select cities in the three scenarios, illustrating how many stations are needed to support different FCEV market-adoption trends, where these stations are needed, and when they are needed. Figure 21 shows the number of stations and average station capacity for select urban areas in 2025. Figure 22 and Figure 23 show the same for 2035 and 2050, respectively. Total capacity of HRSs installed in each urban area are illustrated by circles, with circle color indicating the region. The ZEV region includes states other than California that have adopted the ZEV mandate: Connecticut, Maine, Maryland, Massachusetts, New Jersey, New York, Oregon, Rhode Island, and Vermont. The background colors in the maps shown in Figure 21, Figure 22, and Figure 23 indicate frequency and geographic extent of household vehicle commuting patterns between cities in 11 megaregionsintegrated regional economies that extend across conventional political boundaries - that are useful in capturing large-scale infrastructure and market development trends (Nelson and Rae 2016).

In the early years (2015-2025), the HRS network is limited to California and a few other metropolitan areas, depending on the expansion followed in the different scenarios. Overall, 320-570 HRSs are deployed, supporting 90,000-200,000 FCEVs and providing 9 million to 14 million people access to convenient station networks. Major cities activated by 2025 are similar in California (multiple cities) and the ZEV region (including New York, Boston, and Portland) in all three scenarios, but the cities activated differ in the ROC region. Chicago, Miami, and Denver are activated in the Urban Markets and National Expansion scenarios, while only Seattle is activated in the State Success scenario, due to a high density of early adopters.

In the mid-term period (2025-2035), the HRS network expands significantly, reaching 1,5003,300 total stations, supporting 1.8 million to 4.5 million FCEVs, and providing 38 million to 57 million people access to convenient station networks. The sequence of activating different urban areas varies between scenarios. For example, Chicago plays a significant role in the Urban Markets scenario, with 47 stations and an average station size of $790 \mathrm{~kg} /$ day. By comparison, Chicago has only 26 stations with an average size of $470 \mathrm{~kg} /$ day in the State Success scenario, owing to a more focused expansion in the ZEV states, and it reaches 56 stations with an average capacity of about 1,000 kg/day in the National Expansion scenario. New York City, which is in a ZEV state, experiences the opposite, with more and larger stations deployed in the State Success scenario than in the Urban Markets scenario. The National Expansion scenario remains the most aggressive scenario for all urban areas. In particular, station deployment surges under the National Expansion scenario in Los Angeles (the largest FCEV market across all scenarios), pulling ahead of the State Success scenario's Los Angeles deployment and even further ahead of the Urban Markets scenario's deployment.

By 2050, 7,800-21,000 stations are deployed, supporting 23 million to 61 million FCEVs and enabling reliable station access for 100 million to 215 million people. With the benefit of economies of scale achieved through high volumes of hydrogen demand, large stations become dominant in many major urban areas under all three scenarios. The overall coverage is dictated by the market influences described in Table 2, resulting in an extensive and successful HRS network in all three scenarios. 


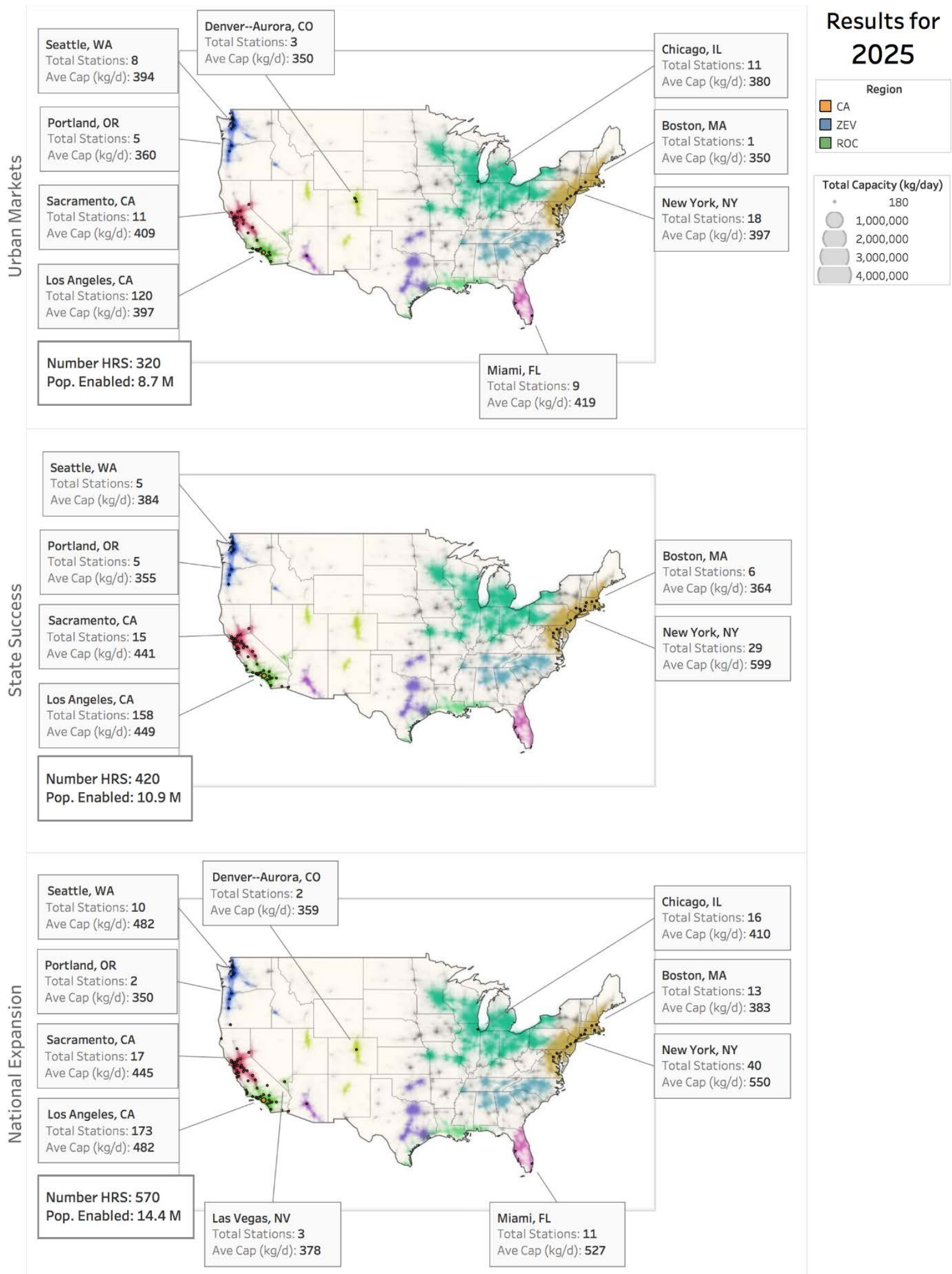

Figure 21. Number of stations and average capacity for select urban areas in $\mathbf{2 0 2 5}$

Note: Connector and destination stations needed to support regional travel are not indicated. 


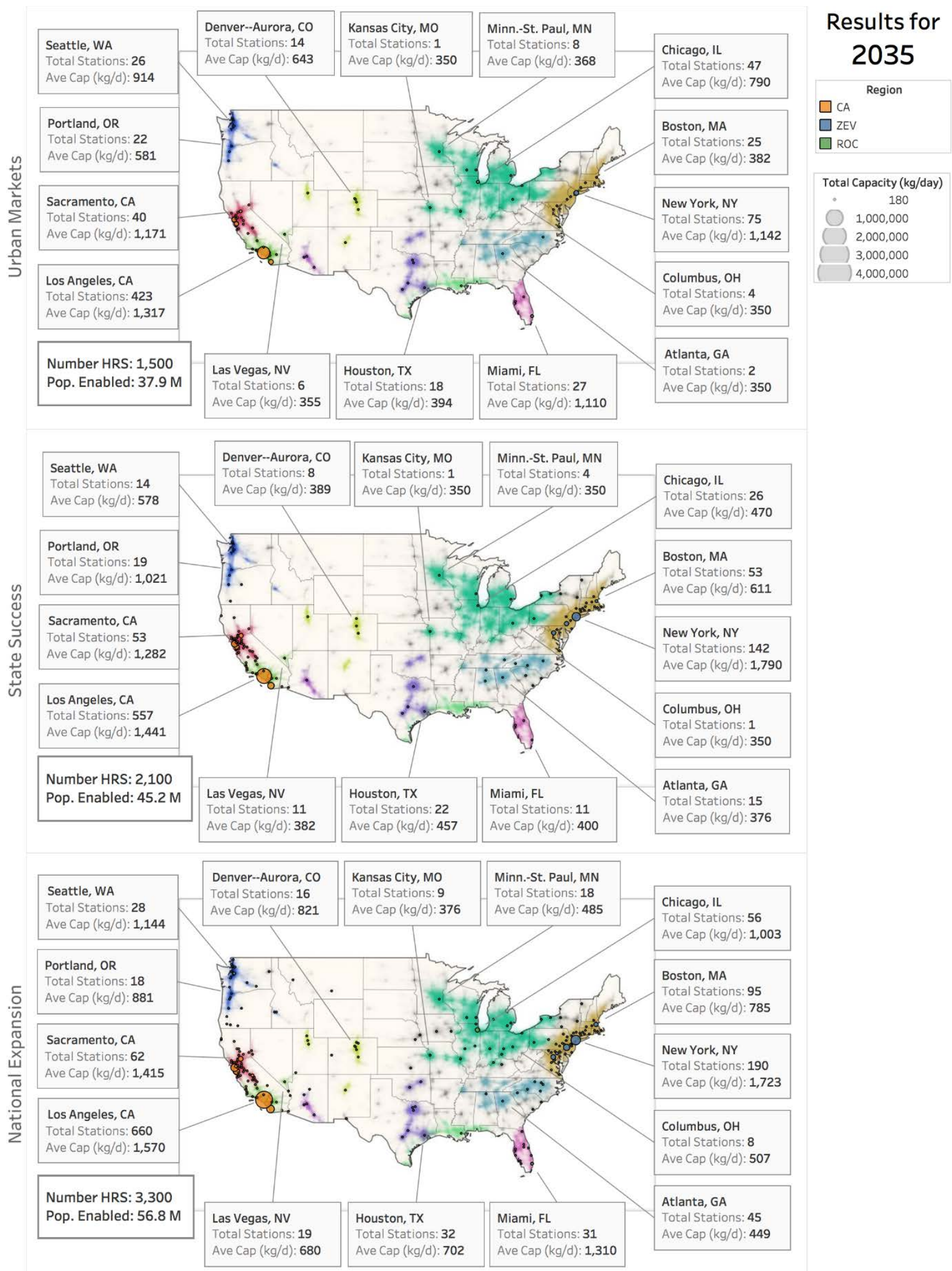

Figure 22. Number of stations and average capacity for select urban areas in $\mathbf{2 0 3 5}$

Note: Connector and destination stations needed to support regional travel are not indicated. 


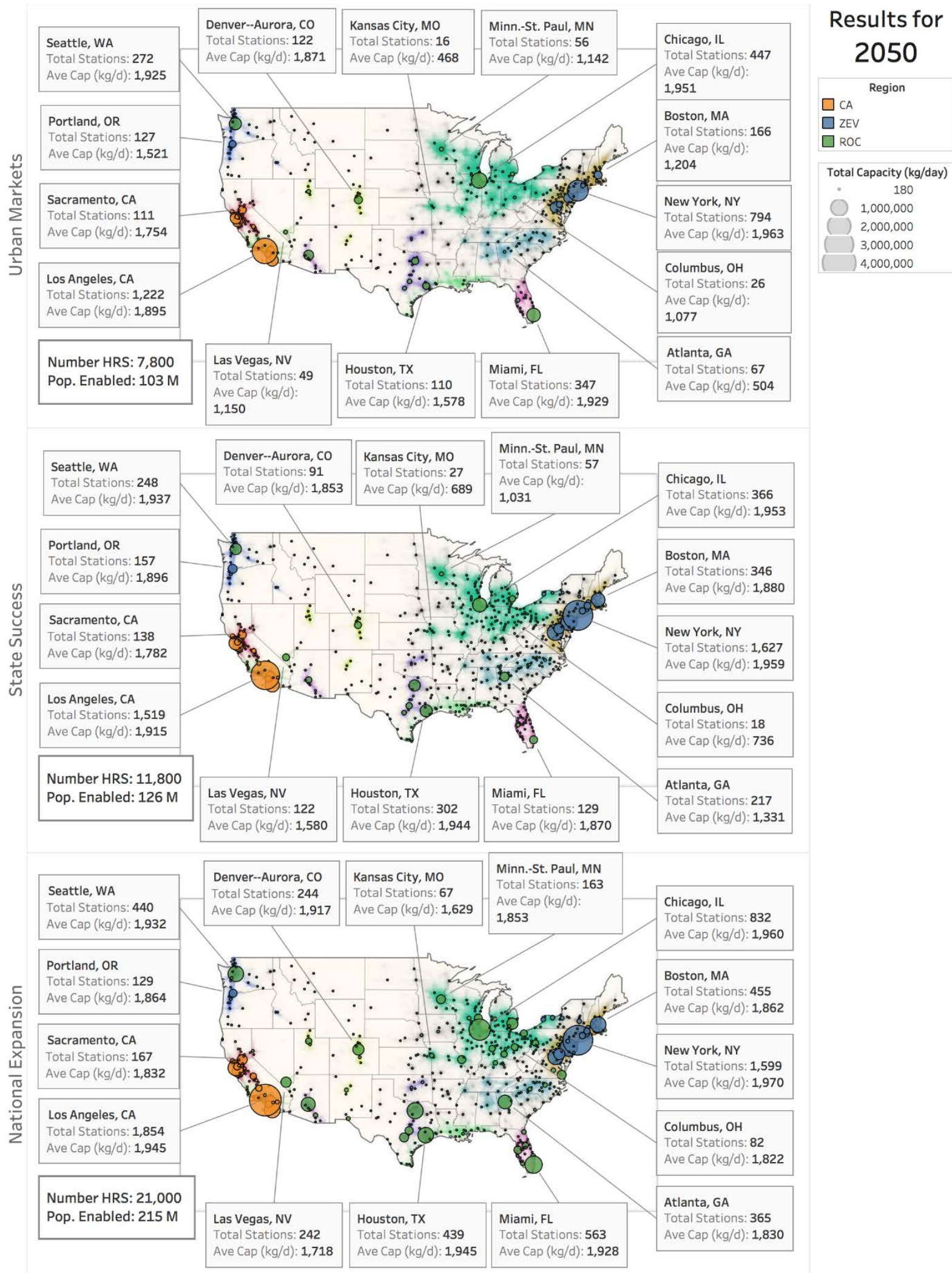

Figure 23. Number of stations and average capacity for select urban areas in $\mathbf{2 0 5 0}$

Note: Connector and destination stations needed to support regional travel are not indicated. 


\subsection{Station Characteristics}

As FCEVs are deployed and the market for hydrogen evolves, the network of refueling stations evolves as well. Figure 24 shows how the hydrogen refueling capacity increases over time in the three scenarios along with average station utilization. The average utilization ramp-up is similar across scenarios because in each scenario the SERA model uses the same deployment strategy to optimize station utilization to contain cost and reduce risk for HRS investors. The relationship between the number of FCEVs on the road and the total HRS capacity is illustrated in Figure 25, showing similar linear expansion trends over time. The general trend across scenarios is that the National Expansion and State Success scenarios tend to have more HRS capacity per total FCEVs deployed as HRS networks continue to expand into new markets over time. By comparison, FCEV market growth (and therefore geographic extent) tends to saturate more quickly in the Urban Markets scenario, as well as to some degree in the State Success scenario.

Figure 26 shows the increase in new station size over time for the three scenarios by region. New station size is determined by the assumed FCEV market growth as well as the characteristics of the urban areas where the stations are progressively built.

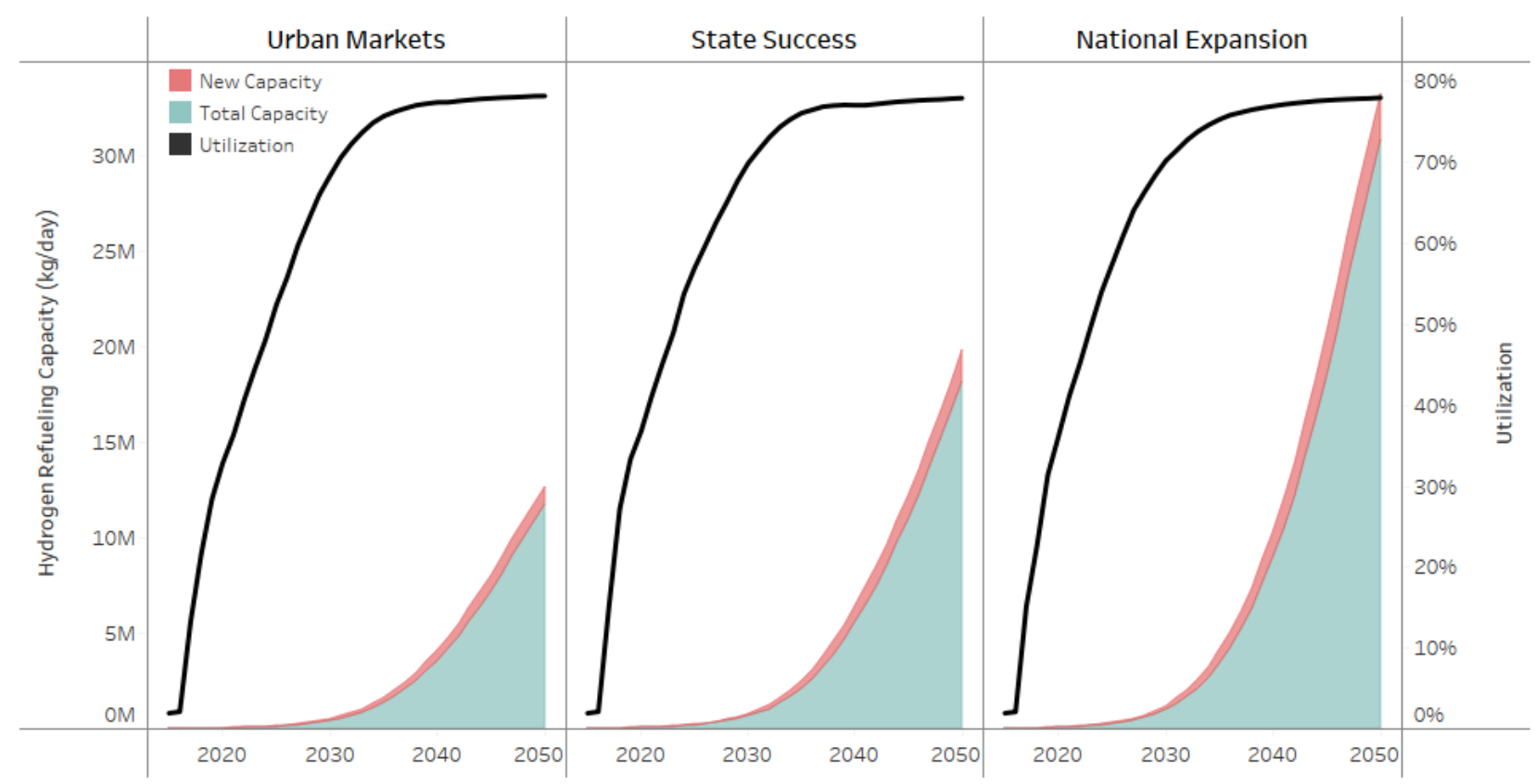

Figure 24. Total and new hydrogen refueling capacity and average station utilization by scenario and over time (Melaina and Penev 2013) 


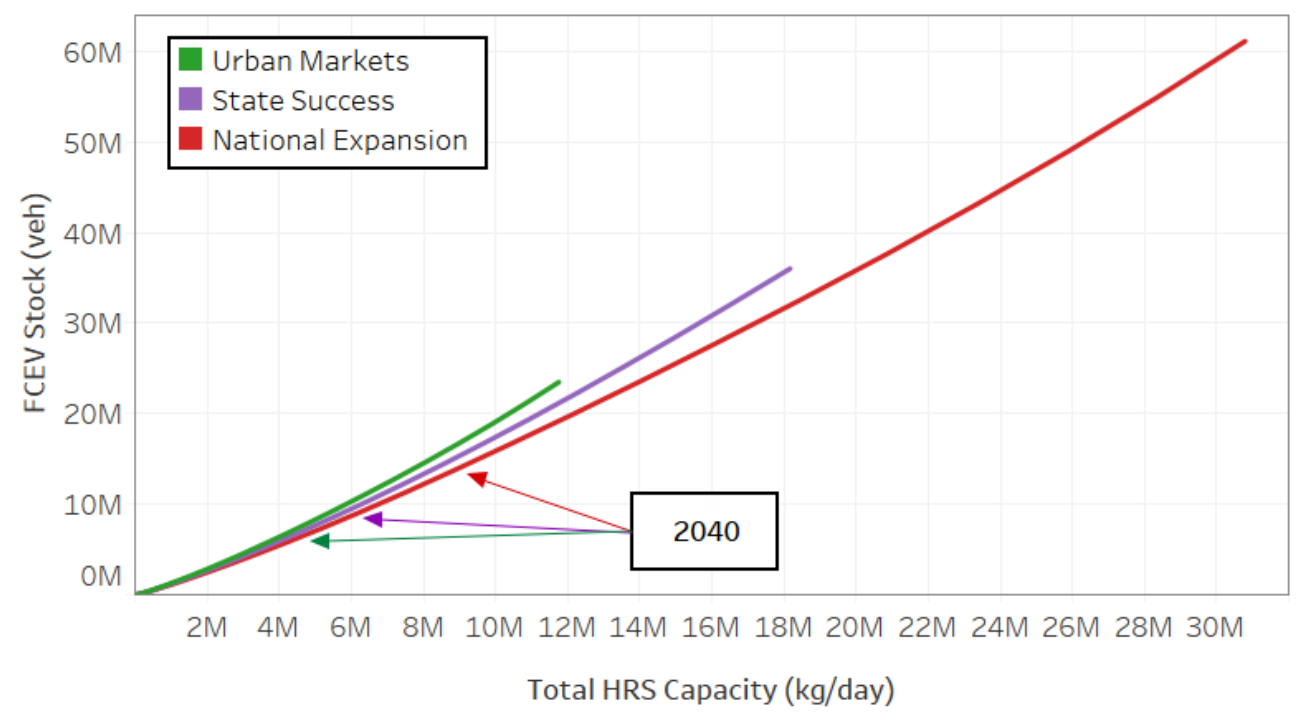

Figure 25. FCEV stock and total HRS capacity by scenario

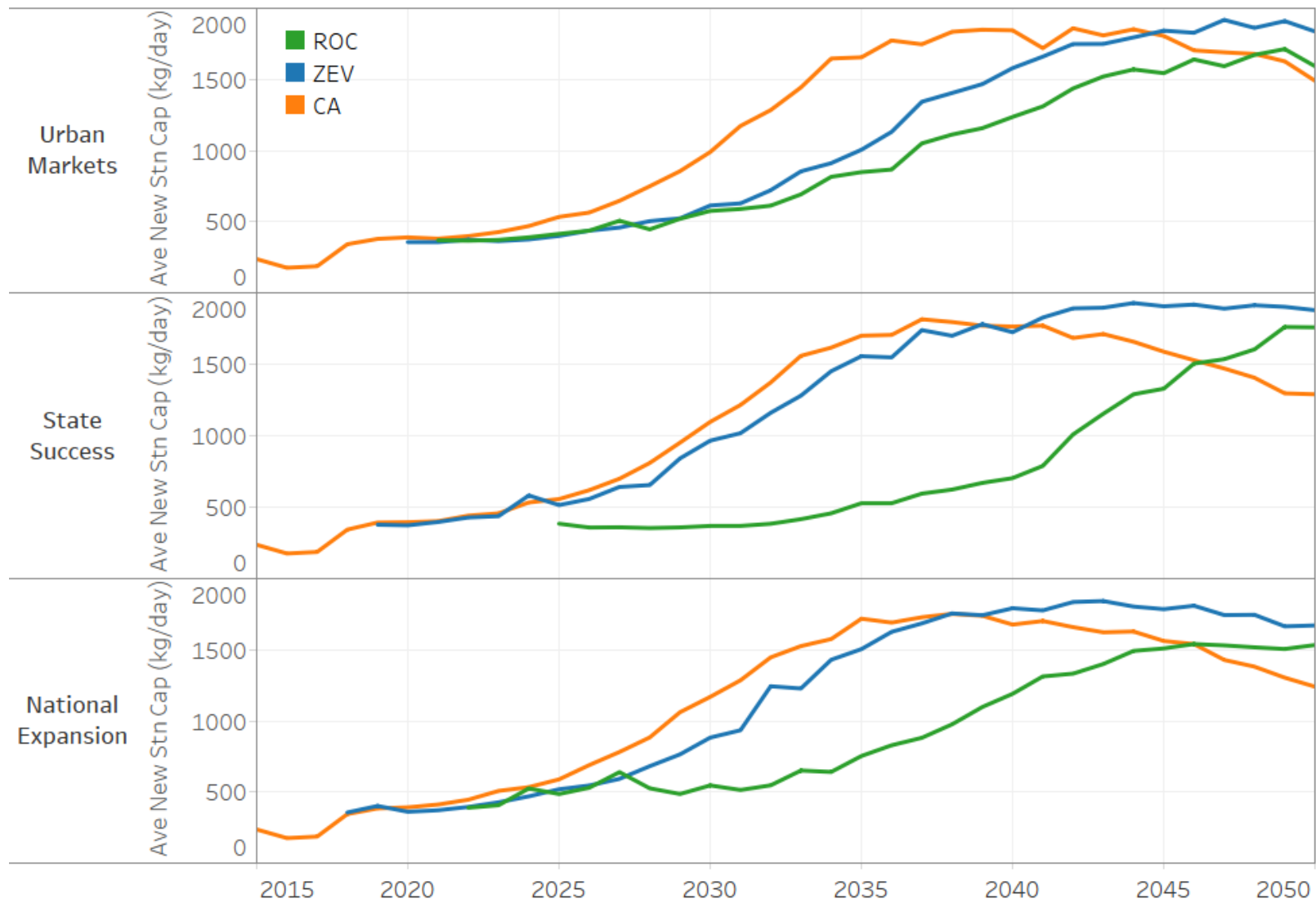

Figure 26. Average capacity of new HRSs deployed over time by region and scenario

Note that the station capacity saturates or decreases in later years because of the addition of small stations in very small urban areas. 
Figure 27 illustrates the total number of stations (by circle size) in 2050 for each scenario and the average capacity of installed HRSs (by color) in different urban areas. For example, in the State Success scenario, the HRS size ranges from $350 \mathrm{~kg} /$ day in small cities (e.g., Reno, Nevada) to almost 2,000 kg/day for metropolitan areas such as Los Angeles and New York.

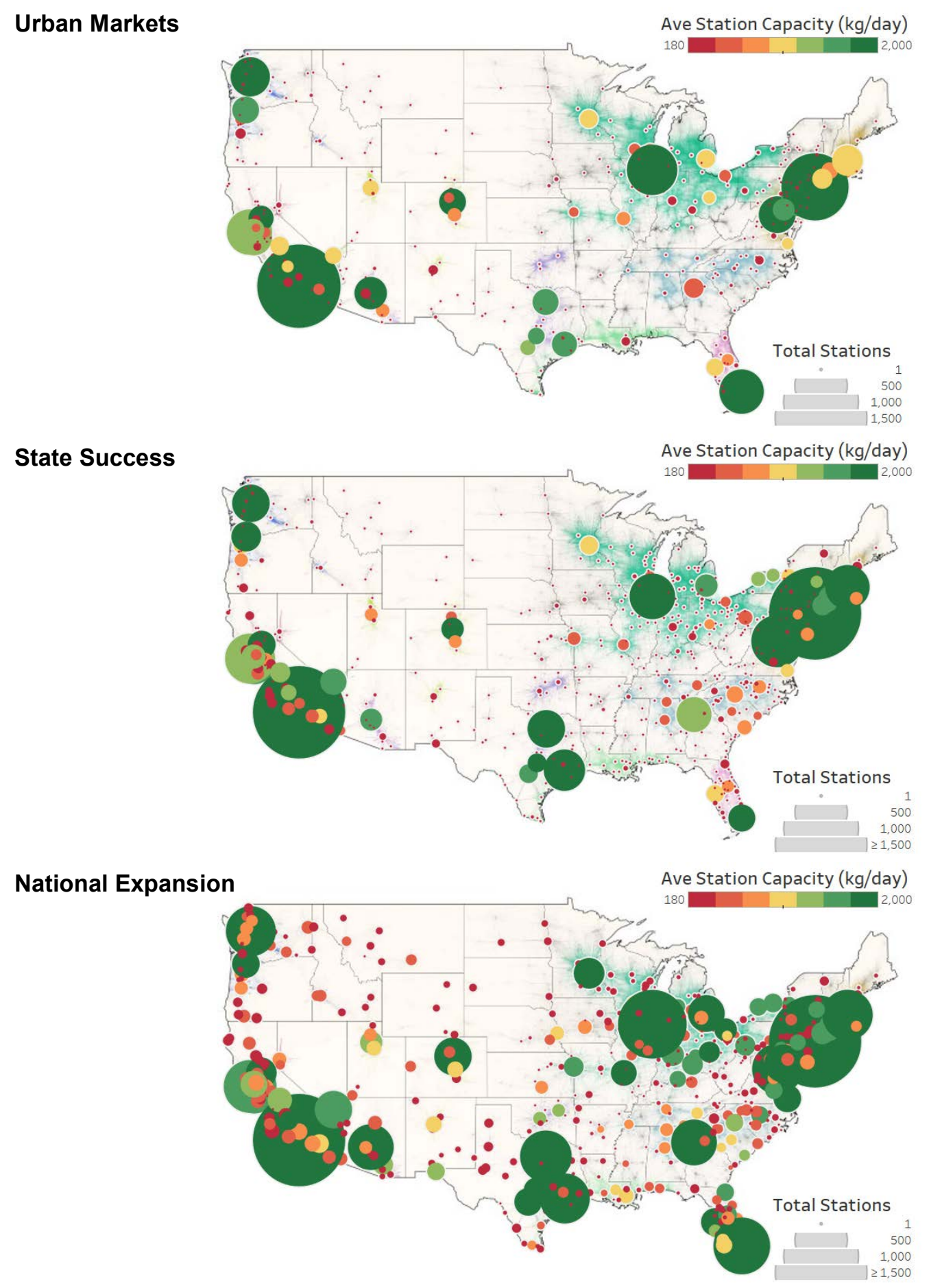

Figure 27. Number and average size of HRSs in 2050 for each scenario 
An HRS network will provide convenient refueling access to a share of the total population based on how many stations are deployed and the population density of the areas in which they are deployed. Each HRS covers a physical area, enabling access to the refueling network to all of the people living, working, or driving within that area. Using detailed traffic simulations, Nicholas and Ogden (2006) estimated a correlation between station availability and city demographics. Figure 28 shows the population with access to a convenient (within $\sim 6$-minute travel distance) HRS for the different scenarios over time (Melaina, Bremson, and Solo 2012). This is proportional to the number of stations deployed in each urban area in a particular year divided by the number of stations required to cover the entire urban area surface, assuming that each station can cover up to 6 square miles (Melaina, Bremson, and Solo 2012). As the HRS network expands, the population enabled approaches the total urban population in each region, opening up greater market opportunities for FCEV adoption.

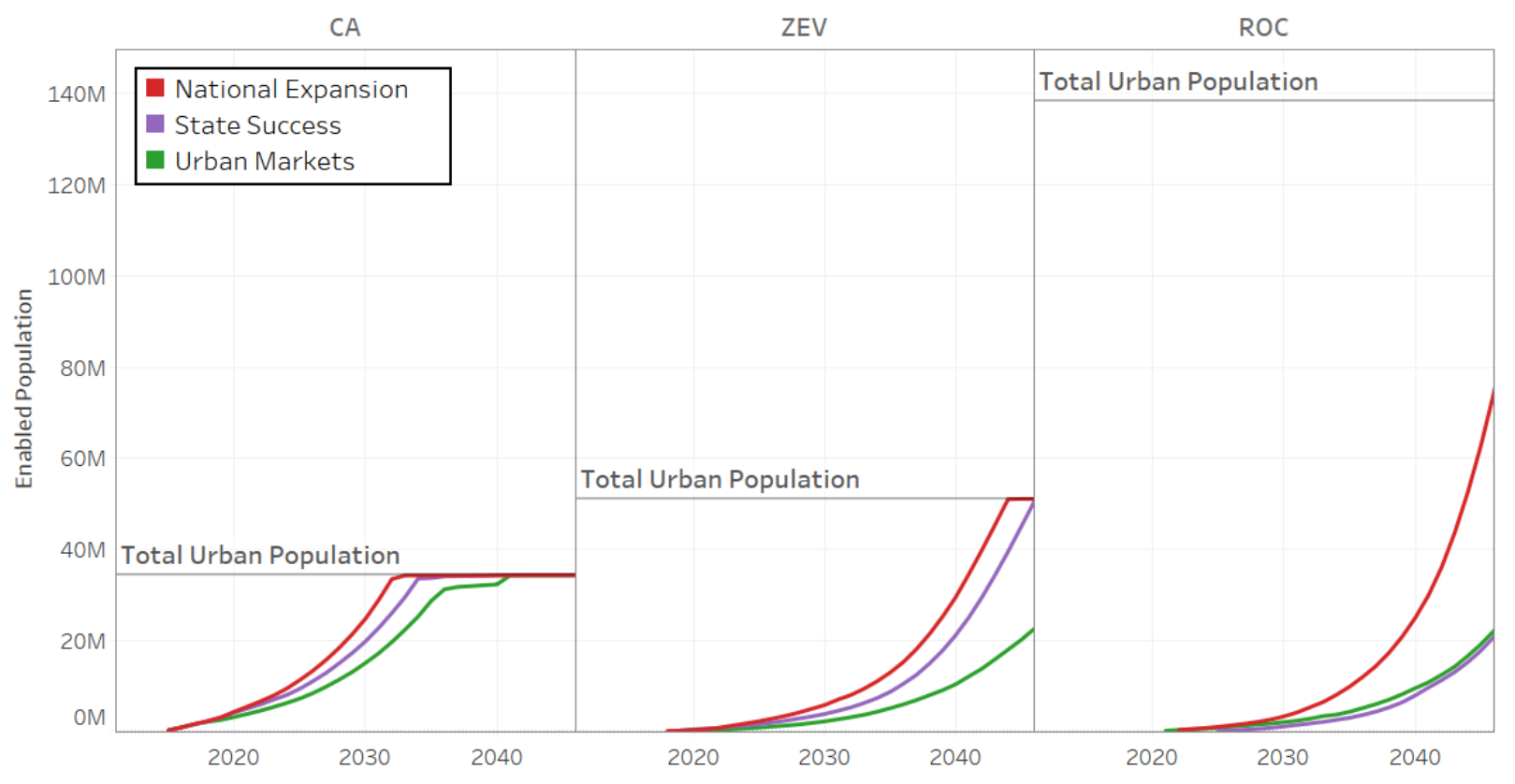

Figure 28. Population with access to hydrogen refueling by scenario 


\section{Concluding Remarks}

This technical report documents the demand-side and refueling infrastructure buildout algorithms of NREL's SERA model, with particular focus on the modeling approach used to simulate the evolution of hydrogen refueling infrastructure to optimize coverage and support adoption. The SERA model follows three major phases to estimate infrastructure required to support passenger FCEV adoption:

\section{Vehicle stock model}

Based on characteristics including annual vehicle sales, vehicle retirement rates, fuel economy, and vehicle miles driven, SERA determines the FCEV stock and the annual demand for hydrogen at an aggregate spatial resolution (e.g., at the state or national level).

\section{Spatial disaggregation}

The hydrogen demand estimated in the previous step is spatially disaggregated into smaller regions, typically at the city level, based on likelihood of early FCEV adoption and strategic sequencing of hydrogen introduction into different regional markets.

\section{Refueling network buildout}

Given the hydrogen demand in each region (typically a city), SERA computes how many refueling stations are required to maximize coverage as well as the size of the stations deployed. It also computes the population that has access to a reliable hydrogen refueling network along with detailed financial performance on a station-by-station basis.

To illustrate the use of the model for simulating HRS deployment scenarios, this report uses as an example the scenarios described in the recent H2USA national hydrogen infrastructure report (Melaina, Bush et al. 2017) and provides an overview of key assumptions and how they influence the results generated by SERA. The information in this report documents the modeling approach and all the key assumptions used by NREL to generate the scenarios reported in the H2USA national hydrogen infrastructure report and can serve as model documentation for the SERA model as well as guidance for stakeholders interested in infrastructure to support the adoption of alternative fuel vehicles.

The demand side of the SERA model estimates the number, size, and locations of HRSs that can satisfy the fuel demand from FCEVs by simulating the system-wide cost-optimal evolution of hydrogen refueling infrastructure. Given the early stage of the FCEV and HRS markets, however, great uncertainty surrounds these model estimates. Lack of empirical data makes it hard to project how FCEV adoption might evolve over time, how vehicles will be used and refueled, and how infrastructure might need to evolve to satisfy consumers' demand. As FCEV and hydrogen infrastructure rollouts proceed, it is important to leverage emerging trends and data on vehicle and station use to update models such as SERA, refine modeling approaches, and validate model results and build confidence in model estimates. Currently, deeper insights into the envelope of uncertainty around the evolution of FCEV adoption could be developed via sensitivity and Monte Carlo analyses. Additionally, as further empirical data become available, recalibration and revalidation studies will be warranted. 


\section{References}

ANL (Argonne National Laboratory). 2017. "The VISION Model."

https://www.anl.gov/es/vision-model.

ANL (Argonne National Laboratory). 2018. "Hydrogen Delivery Scenario Analysis Model (HDSAM)." https://hdsam.es.anl.gov/index.php?content=hdsam.

Baronas, J., G. Achtelik, et al. 2017. Joint Agency Staff Report on Assembly Bill 8: 2017 Annual Assessment of Time and Cost Needed to Attain 100 Hydrogen Refueling Stations in California. Publication Number: CEC-600-2017-011. Sacramento, CA: California Energy Commission and California Air Resources Board. http://www.energy.ca.gov/2017publications/CEC-600-2017011/CEC-600-2017-011.pdf.

BNEF (Bloomberg New Energy Finance). 2017. New Energy Outlook 2017. New York: Bloomberg New Energy Finance.

Brooker, A., J. Gonder, S. Lopp, and J. Ward. 2015. "ADOPT: A Historically Validated Light Duty Vehicle Consumer Choice Model.” SAE Technical Paper: 2015-01-0974.

Brown, T., S. Stephens-Romero, K. Manliclic, J. Soukup, and S. Samuelsen. 2015. Strategic Plan for the Rollout of Hydrogen Fueling Stations in California. CEC-600-2015- 005. Prepared for the California Energy Commission, Irvine, CA: University of California, Irvine. http://www.energy.ca.gov/2015publications/CEC-600-2015-005/CEC-600-2015-005.pdf.

Bush, B., M. Melaina, M. Penev, and W. Daniel. 2013. SERA Scenarios of Early Market Fuel Cell Electric Vehicle Introductions. NREL/TP-5400-5658. Golden, CO: National Renewable Energy Laboratory.

CaFCP (California Fuel Cell Partnership). 2012. A California Road Map: The Commercialization of Hydrogen Fuel Cell Vehicles. West Sacramento, CA: California Fuel Cell Partnership. https://cafcp.org/sites/default/files/A California Road Map June 2012 (CaFCP technical version).pdf.

CaFCP (California Fuel Cell Partnership). 2014. A California Road Map: The Commercialization of Hydrogen Fuel Cell Vehicles. 2014 Update: Hydrogen Progress, Priorities and Opportunities (HyPPO) Report. West Sacramento, CA: California Fuel Cell Partnership. https://cafcp.org/sites/default/files/Roadmap-Progress-Report2014-FINAL.pdf.

CARB (California Air Resources Board). 2017a. 2017 Annual Evaluation of Fuel Cell Electric Vehicle Deployment and Hydrogen Fuel Station Network Development. Sacramento, CA: California Air Resources Board. https://www.arb.ca.gov/msprog/zevprog/ab8/ab8 report 2017.pdf.

CARB (California Air Resources Board). 2017b. "Vision Scenario Planning: Downloads: 2016 Vision 2.1 Limited Release." https://www.arb.ca.gov/planning/vision/downloads.htm. 
DOE (U.S. Department of Energy). 2018. "Current Status of Hydrogen Delivery and Dispensing Costs and Pathways to Future Cost Reductions." DOE Hydrogen and Fuel Cells Program Record 18003.

https://www.hydrogen.energy.gov/pdfs/18003_current_status_hydrogen_delivery_dispensing_co sts.pdf.

Egbue, O. and S. Long. 2012. "Barriers to Widespread Adoption of Electric Vehicles: An Analysis of Consumer Attitudes and Perceptions.” Energy Policy 48: 717-29.

https://doi.org/10.1016/j.enpol.2012.06.009.

EIA (U.S. Energy Information Administration). 2017. Annual Energy Outlook 2017 with Projections to 2050. Washington, DC: U.S. Energy Information Administration.

Heffner, R. R., K. S. Kurani, and T. S. Turrentine. 2007. "Symbolism in California's Early Market for Hybrid Electric Vehicles." Transportation Research Part D: Transport and Environment 12 (6): 396-413. https://doi.org/10.1016/j.trd.2007.04.003.

Hidrue, M. K., G. R. Parsons, W. Kempton, and M. P. Gardner. 2011. "Willingness to Pay for Electric Vehicles and Their Attributes," Resource and Energy Economics 33 (3): 686-705.

IEA (International Energy Agency). 2017. “Global EV Outlook 2017: Two Million and Counting.” Paris: International Energy Agency. https://www.iea.org/publications/freepublications/publication/GlobalEVOutlook2017.pdf.

IHS Markit. 2017. “Automotive.” https://ihsmarkit.com/industry/automotive.html.

IPCC (Intergovernmental Panel on Climate Change). 2014. Climate Change 2014: Mitigation of Climate Change. Contribution of Working Group III to the Fifth Assessment Report of the Intergovernmental Panel on Climate Change. New York: Cambridge University Press.

Kahn, M. and R. Vaughn. 2009. "Greenmarket Geography: The Spatial Clustering of Hybrid Vehicles and LEED Registered Buildings." The B.E. Journal of Economic Analysis \& Policy 9 (2).

KPMG. 2017. KPMG's Global Automotive Executive Survey 2017. Amstelveen: KPMG.

Kuby, M., L. Lines, R. Schultz, Z. Xie, J.-G. Kim, and S. Lim. 2009. “Optimization of Hydrogen Stations in Florida Using the Flow-Refueling Location Model." International Journal of Hydrogen Energy 34 (15): 6045-64. https://doi.org/10.1016/j.ijhydene.2009.05.050.

Leiby, P. and J. Rubin. 2003. "Transitions in Light-Duty Vehicle Transportation: AlternativeFuel and Hybrid Vehicles and Learning." Transportation Research Record: Journal of the Transportation Research Board 1842: 127-34.

McKinney, J., et al. 2015. Joint Agency Staff Report on Assembly Bill 8: Assessment of Time and Cost Needed to Attain 100 Hydrogen Refueling Stations in California. Publication Number: CEC-600-2015-016. Sacramento, CA: California Energy Commission. https://www.energy.ca.gov/2015publications/CEC-600-2015-016/CEC-600-2015-016.pdf. 
Melaina, M. 2003. "Initiating Hydrogen Infrastructures: Preliminary Analysis of a Sufficient Number of Initial Hydrogen Stations in the US." International Journal of Hydrogen Energy 28 (7): 743-55. https://doi.org/10.1016/S0360-3199(02)00240-9.

Melaina, M. 2009. "Discrete Choice Analysis of Consumer Preferences for Refueling Availability." Presented at the DOE Hydrogen and Fuel Cells Program Annual Merit Review and Peer Evaluation Meeting, May 19, 2009. https://www.hydrogen.energy.gov/pdfs/review09/an 05 melaina.pdf.

Melaina, M. and J. Bremson. 2008. "Refueling Availability for Alternative Fuel Vehicle Markets: Sufficient Urban Station Coverage." Energy Policy 36 (8): 3233-41.

Melaina, M., J. Bremson, and K. Solo. 2012. "Consumer Convenience and the Availability of Retail Stations as a Market Barrier for Alternative Fuel Vehicles." Presented at the $31^{\text {st }}$ USAEE/IAEE North American Conference, Austin, Texas. NREL/CP-5600-56898. Golden, CO: National Renewable Energy Laboratory.

Melaina, M., B. Bush, M. Muratori, J. Zuboy and S. Ellis, 2017. National Hydrogen Scenarios: How Many Stations, Where, and When? Prepared by the National Renewable Energy Laboratory for the H2USA Locations Roadmap Working Group. https://www.nrel.gov/docs/fy18osti/71083.pdf.

Melaina, M. and J. Eichman. 2015. Hydrogen Energy Storage: Grid and Transportation Services. NREL/TP-5400-62518. Golden, CO: National Renewable Energy Laboratory. Melaina, M. W., G. Heath, D. Sandor, D. Steward, L. Vimmerstedt, E. Warner, and K. W. Webster. 2013. Alternative Fuel Infrastructure Expansion: Costs, Resources, Production Capacity, and Retail Availability for Low-Carbon Scenarios. Transportation Energy Futures Series. Prepared for the U.S. Department of Energy, Golden, CO: National Renewable Energy Laboratory. https://www.nrel.gov/docs/fy13osti/55640.pdf.

Melaina, M., M. Muratori, J. McLaren, and P. Schwabe. 2017. "Investing in Alternative Fuel Infrastructure: Insights for California from Stakeholder Interviews.” TRB 96th Annual Meeting Compendium of Papers: 17-05279.

Melaina, M. and M. Penev. 2013. Hydrogen Station Cost Estimates: Comparing Hydrogen Station Cost Calculator Results with other Recent Estimates. NREL/TP-5400-56412. Golden, CO: National Renewable Energy Laboratory. https://www.nrel.gov/docs/fy13osti/56412.pdf.

Mohseni, P. and R. G. Stevie. 2010. "Electric Vehicles: Holy Grail or Fool's Gold.” IEEE Power \& Energy Society General Meeting 2010: 1-5.

Muratori, M., B. Bush, C. Hunter, and M. Melaina. 2018. "Modeling Hydrogen Refueling Infrastructure to Support Passenger Vehicles." Energies 11 (5): 1171.

Nelson, G. D. and A. Rae. 2016. "An economic geography of the United States: from commutes to megaregions." PloS one 11 (11): p.e0166083. 
Nicholas, M. A., S. L. Handy, and D. Sperling. 2004. "Using Geographic Information Systems to Evaluate Siting and Networks of Hydrogen Stations." Transportation Research Record 1880: 126-34. https://doi.org/10.3141/1880-15.

Nicholas, M. and J. M. Ogden. 2006. "Detailed Analysis of Urban Station Siting for the California Hydrogen Highway Network." Transportation Research Record: Journal of the Transportation Research Board 1983: 121-128. https://doi.org/10.3141/1983-17.

NRC (National Research Council). 2008. Transitions to Alternative Transportation Technologies: A Focus on Hydrogen. Washington, DC: The National Academies Press. https://www.nap.edu/download/12222.

NRC (National Research Council). 2013. Transitions to Alternative Vehicles and Fuels. Washington, DC: The National Academies Press. https://www.nap.edu/download/18264.

NREL (National Renewable Energy Laboratory). 2017. "H2FAST.” Hydrogen Financial Analysis Scenario Tool. https://www.nrel.gov/hydrogen/h2fast.html.

Ogden, J. M. 1999. "Developing an Infrastructure for Hydrogen Vehicles: A Southern California Case Study," International Journal of Hydrogen Energy 24 (8): 709-30.

Rogers, E. M. 2003. Diffusion of Innovations. Fifth edition. New York: Free Press.

Stephens-Romero, S. D., T. M. Brown, J. E. Kang, W. W. Recker, and G. S. Samuelsen. 2010. "Systematic Planning to Optimize Investments in Hydrogen Infrastructure Deployment." International Journal of Hydrogen Energy 35 (10): 4652-67. https://doi.org/10.1016/i.ijhydene.2010.02.024.

Turton, H. and F. Moura. 2008. "Vehicle-to-Grid Systems for Sustainable Development: An Integrated Energy Analysis.” Technological Forecasting and Social Change 75 (8): 1091-1108.

U.S. Census. 2017. "Current Population Survey Tables for Household Income.” United States Census Bureau. https://www.census.gov/data/tables/time-series/demo/income-poverty/cpshinc.html.

Yang, C. and J. M. Ogden. 2013. "Renewable and Low Carbon Hydrogen for California Modeling the Long Term Evolution of Fuel Infrastructure Using a Quasi-Spatial TIMES Model." International Journal of Hydrogen Energy 38 (11): 4250-65. 